Article

\title{
Brownian Motion and Thermophoretic Diffusion Effects on Micropolar Type Nanofluid Flow with Soret and Dufour Impacts over an Inclined Sheet: Keller-Box Simulations
}

\author{
Khuram Rafique 1®i), Muhammad Imran Anwar ${ }^{1,2,3}$, Masnita Misiran ${ }^{1}$, Ilyas Khan ${ }^{4, *}$, \\ Asiful H. Seikh ${ }^{5}{ }^{(D}$, El-Sayed M. Sherif ${ }^{5,6}{ }^{-}$and Kottakkaran Sooppy Nisar ${ }^{7}(\mathbb{C}$ \\ 1 School of Quantitative Sciences, Universiti Utara Malaysia, Sintok 06010, Kedah, Malaysia; \\ khurram.rafique1005@gmail.com (K.R.); imrananwar@uos.edu.pk (M.I.A.); masnita@uum.edu.my (M.M.)

2 \\ Department of Mathematics, Faculty of Science, University of Sargodha, Sargodha 40100, Pakistan \\ Higher Education Department (HED) Punjab, Lahore 54000, Pakistan \\ Faculty of Mathematics and Statistics, Ton Duc Thang University, Ho Chi Minh City 72915, Vietnam \\ 5 Center of Excellence for Research in Engineering Materials (CEREM), King Saud University, P.O. Box 800, \\ Al-Riyadh 11421, Saudi Arabia; aseikh@ksu.edu.sa (A.H.S.); esherif@ksu.edu.sa (E.-S.M.S.) \\ 6 Electrochemistry and Corrosion Laboratory, Department of Physical Chemistry, National Research Centre, \\ El-Behoth St. 33, Dokki, Cairo 12622, Egypt \\ 7 Department of Mathematics, College of Arts and Sciences, Prince Sattam bin Abdulaziz University, \\ Wadi Al-Dawaser 11991, Saudi Arabia; n.sooppy@psau.edu.sa \\ * Correspondence: ilyaskhan@tdtu.edu.vn
}

Received: 21 September 2019; Accepted: 25 October 2019; Published: 2 November 2019

\begin{abstract}
The principal objective of the current study is to analyze the Brownian motion and thermophoretic impacts on micropolar nanofluid flow over a nonlinear inclined stretching sheet taking into account the Soret and Dufour effects. The compatible similarity transformations are applied to obtain the nonlinear ordinary differential equations from the partial differential equations. The numerical solution of the present study obtained via the Keller-Box technique. The physical quantities of interest are skin friction, Sherwood number, and heat exchange, along with several influences of material parameters on the momentum, temperature, and concentration are elucidated and clarified with diagrams. A decent settlement can be established in the current results with previously published work in the deficiency of incorporating effects. It is found that the growth of the inclination and nonlinear stretching factor decreases the velocity profile. Moreover, the growth of the Soret effect reduces the heat flux rate and wall shear stress.
\end{abstract}

Keywords: Keller-Box Simulations; micropolar nanofluid; MHD; power law; Soret effect; Dufour effect; inclined surface

\section{Introduction}

The investigation of boundary layer flow and heat exchange over a stretching surface has pulled in consideration of numerous specialists because of its immense mechanical and industrial applications in the field of industry metallurgical procedures, tinning of copper wires, assembling of plastic, elastic sheets, and fiber. The viscous fluid flow over uniform surface started by Sakiadis, [1]. Moreover, Crane [2] studied the closed-form solution of the boundary layer flow over a stretching sheet. The boundary layer flow of dusty fluid over an inclined surface with the heat source/sink presented by Ramesh et al. [3]. Singh [4] investigated heat and mass exchange of viscous fluid flow on a porous inclined plate by incorporating the viscous dissipation. Similarity solution of magnetohydrodynamic 
flow over an inclined sheet calculated by Ali et al. [5]. Ramesh et al. [6] worked on the boundary layer flow over an inclined sheet with convective boundaries. MHD free convection dissipative fluid flow past over a slanted porous surface scrutinized by Malik [7]. Hayat et al. [8] probed radiation effect on the flow induced by stretching cylinder by considering non-uniform heat source/sink. Balla et al. [9] examined an inclined cavity packed with nanofluid saturated in a porous medium.

Choi [10] first time introduced the nanofluid, which is a particular class of fluids and nanotechnology is based on the nanofluid becoming a large field of research among the researchers during the last few decades. Nanofluids are prepared by the stable and uniform suspensions of nanometer-sized solid particles called nanoparticles $\left(\mathrm{Al}_{2} \mathrm{O}_{3}, \mathrm{Cu}\right.$, and $\left.\mathrm{CuO}\right)$ in the base liquids. Nanofluid has numerous important applications in engineering and technology and is widely used for thermal processes at the industrial level. Choi [10] described these suspensions of nanoparticles could be used for the enhancement of the thermal conductivity of other fluids because these are unique in thermal, mechanical, optical, electrical, and magnetic properties. He pointed out that nanofluid is the best candidate for heat and mass exchange when these are associated with the other fluids. Moreover, Nakhjavani et al. [11] conducted an experimental study on the synthesis of nanoparticles from the green tea leaves. On the other hand, sedimentation and instability of the nanoparticles have been a big challenge for the scientists. Kamalgharibi et al. [12] studied the effects of different factors on the stability of nanoparticles. The factors that play an important role in upgrading the thermal conductivity of nanofluid have been studied by Buongiorno [13]. The heat exchange of nanofluid over a nonlinear permeable sheet is numerically discussed by Zaimi et al. [14]. Anwar et al. [15] studied the numerical study of micropolar nanofluid flow over a stretching sheet. Nanofluid flow over an inclined stretching surface reviewed by Sandeep and Kumar [16]. They investigated the heat and mass exchange of dusty nanoparticles enhanced because of the volume fraction of nanoparticles. Suriyakumar and Devi [17] expressed the effects of internal heat generation and suction on mixed convective nanofluid flow through an inclined surface. Ziaei-Rad et al. [18] examined the similarity solution of the boundary layer nanofluid flow on an inclined surface. Rashad [19] studied nanofluid flow by considering convective boundaries and anisotropic slip effect. Mitra [20] investigated computational modeling of nanofluid flow over a heated inclined plate. Khan et al. [21] illustrated the heat and mass transfer of MHD Jeffery nanofluid flow over an inclined sheet. Hatami et al. [22] discussed three-dimensional steady nanofluids over an inclined disk. Recently, Rafique et al. [23] investigated the Casson nanofluid flow towards an inclined surface and found that the inclination effect retards the velocity profile.

Whenever heat and mass exchange happens at the same time between the fluxes, the energetic potential behaves differently, as an energy flux can be created by temperature gradients as well as by composition rises. Dufour impacts are the energy flux produced due to composition gradients. Besides, Soret or thermal diffusion is the mass flux produced due to temperature gradients. Mostly, diffusion thermo and thermal diffusion effects are neglected in the heat and mass exchange procedures, as these impacts are less in magnitude as compared to the results described by the Fourier's or Fick's laws. There are, be that as it may, special cases. The Soret impact, for example, has been used for isotope partition, and in mixtures between gases with light sub-atomic weight $\left(\mathrm{H}_{2}, \mathrm{He}\right)$. For medium sub-atomic weight $\left(\mathrm{N}_{2} \mathrm{~N}_{2}\right.$, air), the Dufour impact cannot be neglected due to the significance magnitude [24]. Beg et al. [25] calculated the Soret and Dufour properties over a slanted plate. Moreover, Paul and Chatterjee [26] investigated the Soret and Dufour effects on power-law fluid over an inclined plate. Besides, Soret and Dufour effects over an inclined cavity were examined by Balla and Naikoti [27].

The idea of micropolar fluid manages a class of liquids that show specific microscopic impacts developing by the confined configuration and micro motions of the fluid elements. These liquids have diluted interruptions of rigid macromolecules with irregular motion, which support pressure, body moments and are effected by spin inertia. The fundamentals of micropolar fluids that began by the hypothesis of Eringen [28,29] have a vital region of examination due to their uses in various procedures that happen in manufacturing. Such applications incorporate the flow of exotic greases, colloidal interruptions, hardening of fluid precious stones, the expulsion of polymer 
fluids, creature plasma, and body-liquids as well as numerous different circumstances. A fantastic audit about the micropolar fluid and its uses explored by Ariman et al. [30], Qukaszewicz [31], and Eringen [32]. Rahman et al. [33] discussed the flow of micropolar liquid by considering the variable properties. Micropolar fluid flow by taking different effects over an inclined sheet studied by Das, [34]. Kasim et al. [35] examined the micropolar fluid flow on the inclined plate numerically. Srinivasacharya and Bindu [36] explored micropolar fluid flow through a slanted channel having parallel plates. Hazbavi and Sharhani, [37] examined the flow of micropolar fluid between two parallel plates with a constant pressure gradient. Shamshuddin et al. [38] studied the heat and mass transfer of micropolar fluid flow through the permeable inclined plate. The effect of double dispersion on micropolar fluid flow over an inclined surface discussed by Srinivasacharya et al. [39]. Newly, Rafique et al. [40] examined the micropolar nanofluid flow on an inclined surface via a numerical technique.

Keeping in mind the above literature review, the present problem is focused on micropolar nanofluid flow over an inclined stretching surface with Soret and Dufour effects. Similar work is not reported in the literature, and therefore, the present study will fill this gape. Besides, this field of research has important applications in industry and engineering. The model under concern is novel, and all numerical outcomes found from the present problem are new.

\section{Problem Formulation}

A steady, two-dimensional boundary layer flow of micropolar nanofluid over a nonlinear inclined stretching surface by considering an angle $\gamma$. The stretching and free stream velocities are taken as, $u_{w}(x)=a x^{m}$ and $u_{\infty}(x)=0$. An external transverse magnetic field is assumed normal to the flow path. It is supposed that the electric and magnetic field properties are very small as the magnetic Reynolds number is negligible in Mishra et al. [41]. The micropolar finite-size particles, along with nanoparticles, are continuously distributed in the base fluids. The Brownian motion and thermophoresis effects are taken into account. The temperature $T$ and nanoparticle fraction $C$ at the wall take the constant values $T_{w}$ and $C_{w}$, while the ambient forms for nanofluid mass and temperature fractions $C_{\infty}$ and $T_{\infty}$ are attained as $y$ tends to infinity shown in Figure 1.

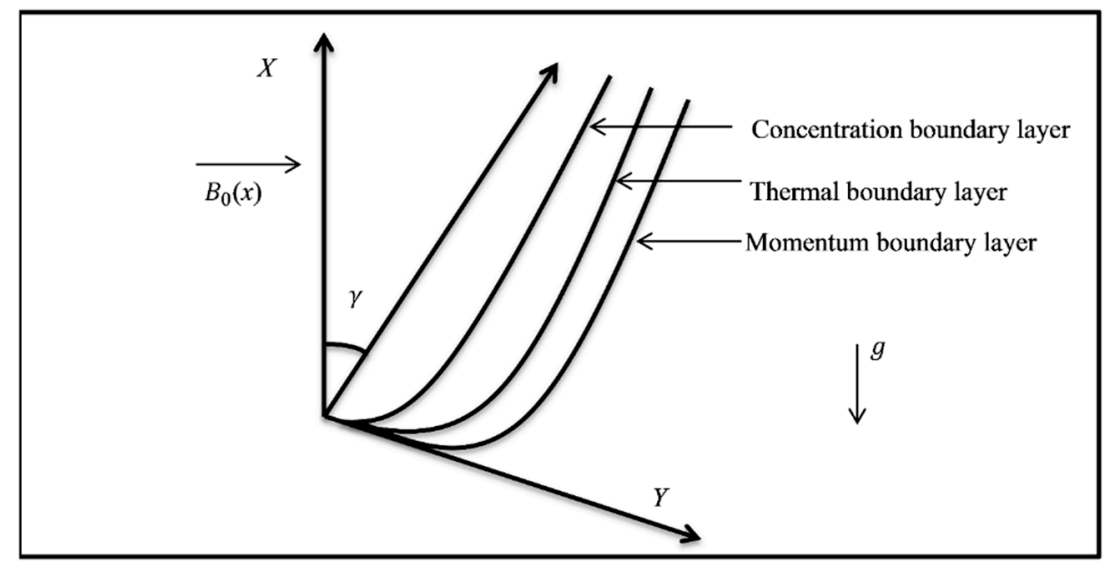

Figure 1. Physical geometry and coordinate system.

The flow equations for this study were given by Khan and Pop [42] and Anwar et al. [15]:

$$
\begin{gathered}
\frac{\partial u}{\partial x}+\frac{\partial v}{\partial y}=0 \\
u \frac{\partial u}{\partial x}+v \frac{\partial v}{\partial y}=\left(\frac{\mu+k_{1}^{*}}{\rho}\right) \frac{\partial^{2} u}{\partial y^{2}}+\left(\frac{k_{1}^{*}}{\rho}\right) \frac{\partial N^{*}}{\partial y}+g\left[\beta_{t}\left(T-T_{\infty}\right)+\beta_{c}\left(C-C_{\infty}\right)\right] \cos \gamma-\frac{\sigma B_{0}^{2}(x)}{\rho} u
\end{gathered}
$$




$$
\begin{gathered}
u \frac{\partial N^{*}}{\partial x}+v \frac{\partial N^{*}}{\partial y}=\left(\frac{\gamma^{*}}{j^{*} \rho}\right) \frac{\partial^{2} N^{*}}{\partial y^{2}}-\left(\frac{k_{1}^{*}}{j^{*} \rho}\right)\left(2 N^{*}+\frac{\partial u}{\partial y}\right), \\
u \frac{\partial T}{\partial x}+v \frac{\partial T}{\partial y}=\alpha \frac{\partial^{2} T}{\partial y^{2}}+\tau\left[D_{B} \frac{\partial C}{\partial y} \frac{\partial T}{\partial y}+\frac{D_{T}}{T_{\infty}}\left(\frac{\partial T}{\partial y}\right)^{2}\right]+\frac{D_{T} K_{T}}{C_{S} C_{p}} \frac{\partial^{2} C}{\partial y^{2}} \\
u \frac{\partial C}{\partial x}+v \frac{\partial C}{\partial y}=D_{B} \frac{\partial^{2} C}{\partial y^{2}}+\frac{D_{T} K_{T}}{T_{\infty}} \frac{\partial^{2} T}{\partial y^{2}}
\end{gathered}
$$

where $u$ and $v$ are the velocity components in the directions of $x$ and $y$ respectively, $g$ is the gravitational acceleration, strength of magnetic field is defined by $B_{0}, \sigma$ is the electrical conductivity, viscosity is given by $\mu$, density of conventional fluid is given by $\rho_{f}$, density of the nanoparticle is given by $\rho_{p}$, thermal expansion factor is denoted by $\beta_{t}$, concentration expansion constant is given by $\beta_{c}$, $D_{B}$ signifies the Brownian dissemination factor and $D_{T}$ represents the thermophoresis dispersion factor, $k$ denotes the thermal conductivity, $\alpha=\frac{k}{(\rho c)_{f}}$ denotes thermal diffusivity parameter, and the symbolic representation of the relation among current heat capacity of the nanoparticle and the liquid is $\tau=\frac{(\rho c)_{p}}{(\rho c)_{f}}$.

The boundary settings are:

$$
\begin{gathered}
u=u_{w}(x)=a x, v=0, N^{*}=-m_{0} \frac{\partial u}{\partial y}, T=T_{w}, C=C_{w} \text { at } y=0, \\
u \rightarrow u_{\infty}(x)=0, v \rightarrow 0, N^{*} \rightarrow 0, T \rightarrow T_{\infty}, C \rightarrow C_{\infty} \text { as } y \rightarrow \infty .
\end{gathered}
$$

Here $\psi=\psi(x, y)$ is, the stream function, which is demarcated as:

$$
u=\frac{\partial \psi}{\partial y}, v=-\frac{\partial \psi}{\partial x}
$$

Equation (1) is fulfilled. The compatible transformations are demarcated as:

$$
\begin{gathered}
\psi=\sqrt{\frac{2 v a x^{m+1}}{m+1}} f(\eta), \eta=y \sqrt{\frac{(m+1) a x^{m+1}}{2 v}}, N^{*}=a x^{m} \sqrt{\frac{a(m+1) x^{m-1}}{2 v}}, \\
\theta(\eta)=\frac{T-T_{\infty}}{T_{w}-T_{\infty}}, \phi(\eta)=\frac{C-C_{\infty}}{C_{w}-C_{\infty}} .
\end{gathered}
$$

On substituting Equation (8), the system of Equations (2)-(5) converted to:

$$
\begin{gathered}
(1+K) f^{\prime \prime \prime}+f f^{\prime \prime}-\left(\frac{2 m}{m+1}\right) f^{\prime 2}+K h^{\prime}+\left(\frac{2}{m+1}\right)(\lambda \theta+\delta \phi) \cos \gamma-\left(\frac{2 M}{m+1}\right)\left(f^{\prime}\right)=0 \\
\left(1+\frac{K}{2}\right) h^{\prime \prime}+f h^{\prime}-\left(\frac{3 m-1}{m+1}\right) f^{\prime} h-\left(\frac{2 K}{m+1}\right)\left(2 h+f^{\prime \prime}\right)=0 \\
\left(\frac{1}{\operatorname{Pr}}\right) \theta^{\prime \prime}+f \theta^{\prime}+N b \phi^{\prime} \theta^{\prime}+N t \theta^{\prime 2}+D_{f} \phi^{\prime \prime}=0 \\
\phi^{\prime \prime}+\operatorname{Lef} \phi^{\prime}+\operatorname{SrLe} \theta^{\prime \prime}=0 .
\end{gathered}
$$

where,

$$
\begin{gathered}
\lambda=\frac{G r_{x}}{\operatorname{Re}_{x}^{2}}, \delta=\frac{G c_{x}}{\operatorname{Re}^{2} x}, M=\frac{\sigma B_{0}^{2}(x)}{a \rho}, L e=\frac{v}{D_{B}}, \operatorname{Pr}=\frac{v}{\alpha}, \\
N b=\frac{\tau D_{B}\left(C_{w}-C_{\infty}\right)}{v}, N t=\frac{\tau D_{T}\left(T_{w}-T_{\infty}\right)}{v T_{\infty}}, G r_{x}=\frac{g \beta_{t}\left(T_{w}-T_{\infty}\right) x^{3}}{v^{2}}, \\
\operatorname{Re}_{x}=\frac{u_{w}(x) x}{v}, G c_{x}=\frac{g \beta_{c}\left(C_{w}-C_{\infty}\right) x^{3}}{v^{2}}, D f=\frac{D_{T} K_{T}\left(C_{w}-C_{\infty}\right)}{v C_{s} C_{p}\left(T_{w}-T_{\infty}\right)}, \\
S r=\frac{D_{T} K_{T}\left(T_{w}-T_{\infty}\right)}{v T_{\infty}\left(C_{w}-C_{\infty}\right)} .
\end{gathered}
$$

Here, primes mean the differentiation with respect to $\eta, M$ denotes the magnetic factor, $v$ denotes the liquid kinematic viscosity, Prandtl number is symbolized by $\mathrm{Pr}$, Lewis number is denoted by Le, the material parameter represented by $K, D f$ means the Dufour factor, and $S r$ indicates the Soret factor. 
The corresponding boundary settings are changed to:

$$
\begin{gathered}
f(\eta)=0, f^{\prime}(\eta)=1, h(\eta)=0, \theta(\eta)=1, \phi(\eta)=1, \text { at } \eta=0, \\
f^{\prime}(\eta) \rightarrow 0, h(\eta) \rightarrow 0, \theta(\eta) \rightarrow 0, \phi(\eta) \rightarrow 0, \text { at } \eta \rightarrow \infty .
\end{gathered}
$$

The concerned physical quantities including $C_{f}, N u$, and $S h$ (skin friction, Nusselt number, and Sherwood number) are demarcated as:

$$
C_{f}=\frac{\tau_{w}}{\rho u_{w}^{2}}, N u=\frac{x q_{w}}{k\left(T_{w}-T_{\infty}\right)}, S h=\frac{x q_{m}}{D_{B}\left(C_{w}-C_{\infty}\right)} .
$$

The associated expressions of $C_{f x}(0)=(1+K) f^{\prime \prime}(0),-\theta^{\prime}(0)$, and $-\phi^{\prime}(0)$ are defined as:

$$
C_{f x}(0)=C_{f} \sqrt{\frac{2}{m+1} \operatorname{Re}_{x}},-\theta^{\prime}(0)=\frac{N u}{\sqrt{\operatorname{Re}_{x}(m+1 / 2)}},-\phi^{\prime}(0)=\frac{S h}{\sqrt{\operatorname{Re}_{x}(m+1 / 2)}} .
$$

where $\operatorname{Re}_{x}=u_{w}(x) x / v$, is the local Reynolds number based on the stretching velocity. The converted nonlinear differential Equations (9)-(12) with the boundary conditions (14) are elucidated by the Keller-box scheme consisting of the steps as finite-differences technique, Newton's scheme and block elimination process clearly explained by Anwar et al. [15]. This method has been extensively applied via Matlab software and it looks to be the most flexible as compared to common techniques. It has been presented to be much quicker, easier to program, more efficient, and more comfortable to practice.

\section{Results and Discussion}

This portion of the study managed the calculated results of converted nonlinear ordinary differential Equations (9)-(12) with boundary settings (14) elucidated via the Keller-box method. For the numerical result of physical parameters of our concern including Brownian motion parameter $N b$, thermophoresis parameter $N t$, magnetic factor $M$, buoyancy factor $\lambda$, solutal buoyancy factor $\delta$, inclination factor $\gamma$, Prandtl number Pr, Lewis number $L e$, Dufour effect $D f$, Soret effect $S r$, non-linear stretching parameter $m$, and material factor $K$ several figures and tables were prepared. In Table 1 , in the deficiency of the Dufour effect, buoyancy parameter, solutal buoyancy constraint, magnetic factor, and material factor with $m=1, S r=0.1$, and $\gamma=90^{\circ}$ outcomes of reduced Nusselt number $-\theta^{\prime}(0)$ reduced Sherwood number $-\phi^{\prime}(0)$ were equated by existing findings of Khan and Pop [42]. The consequences established a brilliant settlement. The effects of $-\theta^{\prime}(0),-\phi^{\prime}(0)$ and $C_{f x}(0)$ beside changed values of involved physical factors $N b, N t, L e, S r, D f, M, m, K, \delta, \lambda, \gamma$, and Pr are shown in Table 2. From Table 2 it is seen that $-\theta^{\prime}(0)$ declines for growing the values of $N b, N t, M L e, \operatorname{Pr}, S r, D f, m, \gamma$, and increased by enhancing the numerical values of $\lambda, \delta$, and $K$. Moreover, it is perceived that $-\phi^{\prime}(0)$ enhanced with the larger values of $N b, \lambda, \delta, N t, L e, K, \operatorname{Pr}, D f, S r$, and drops for bigger values of $M, m$, and $\gamma$. On the other hand, $C_{f x}(0)$ rises with the growing values of $N b, N t, L e, M, K, \operatorname{Pr}, m, D f, \gamma$, and drops

\begin{tabular}{|c|c|c|c|c|c|}
\hline \multirow{2}{*}{$N b$} & \multirow{2}{*}{$N t$} & \multicolumn{2}{|c|}{ Khan and Pop [42] } & \multicolumn{2}{|c|}{ Present Results } \\
\hline & & $-\theta^{\prime}(0)$ & $-\phi^{\prime}(0)$ & $-\theta^{\prime}(0)$ & $-\phi^{\prime}(0)$ \\
\hline 0.1 & 0.1 & 0.9524 & 2.1294 & 0.9524 & 2.1294 \\
\hline 0.2 & 0.2 & 0.3654 & 2.5152 & 0.3654 & 2.5152 \\
\hline 0.3 & 0.3 & 0.1355 & 2.6088 & 0.1355 & 2.6088 \\
\hline 0.4 & 0.4 & 0.0495 & 2.6038 & 0.0495 & 2.6038 \\
\hline 0.5 & 0.5 & 0.0179 & 2.5731 & 0.0179 & 2.5731 \\
\hline
\end{tabular}
with the higher values of $\lambda, \delta$, and $S r$.

Table 1. Contrast of the reduced Nusselt number $-\theta^{\prime}(0)$ and the reduced Sherwood number $-\phi^{\prime}(0)$ when $M, K, D f, \lambda, \delta=0$, and $S r=0.1, m=1, L e=\operatorname{Pr}=10$, and $\gamma=90^{\circ}$. 
Table 2. Values of $-\theta^{\prime}(0),-\phi^{\prime}(0)$, and $C_{f x}(0)$.

\begin{tabular}{ccccccccccccccc}
\hline $\mathbf{N b}$ & $\boldsymbol{N} \boldsymbol{t}$ & $\mathbf{P r}$ & $\boldsymbol{L} \boldsymbol{e}$ & $\boldsymbol{M}$ & $\boldsymbol{K}$ & $\boldsymbol{\lambda}$ & $\boldsymbol{\delta}$ & $\boldsymbol{S r}$ & $\boldsymbol{D f}$ & $\boldsymbol{m}$ & $\boldsymbol{\gamma}$ & $-\boldsymbol{\theta}^{\prime} \mathbf{( 0 )}$ & $-\boldsymbol{\phi}^{\prime} \mathbf{( 0 )}$ & $\boldsymbol{C}_{f x} \mathbf{( 0 )}$ \\
\hline 0.1 & 0.1 & 7.0 & 5.0 & 0.1 & 1.0 & 0.1 & 0.9 & 0.1 & 0.1 & 0.5 & $45^{0}$ & 0.6675 & 1.6243 & 0.9558 \\
$\mathbf{0 . 3}$ & 0.1 & 7.0 & 5.0 & 0.1 & 1.0 & 0.1 & 0.9 & 0.1 & 0.1 & 0.5 & $45^{0}$ & 0.1634 & 1.8170 & 0.9590 \\
0.1 & $\mathbf{0 . 3}$ & 7.0 & 5.0 & 0.1 & 1.0 & 0.1 & 0.9 & 0.1 & 0.1 & 0.5 & $45^{0}$ & 0.2360 & 1.7656 & 0.9589 \\
0.1 & 0.1 & $\mathbf{1 0 . 0}$ & 5.0 & 0.1 & 1.0 & 0.1 & 0.9 & 0.1 & 0.1 & 0.5 & $45^{0}$ & 0.4982 & 1.7180 & 0.9567 \\
0.1 & 0.1 & 7.0 & $\mathbf{1 0 . 0}$ & 0.1 & 1.0 & 0.1 & 0.9 & 0.1 & 0.1 & 0.5 & $45^{0}$ & -0.1126 & 3.0497 & 1.0268 \\
0.1 & 0.1 & 7.0 & 5.0 & $\mathbf{0 . 5}$ & 1.0 & 0.1 & 0.9 & 0.1 & 0.1 & 0.5 & $45^{0}$ & 0.6555 & 1.5786 & 1.2956 \\
0.1 & 0.1 & 7.0 & 5.0 & 0.1 & $\mathbf{5 . 0}$ & 0.1 & 0.9 & 0.1 & 0.1 & 0.5 & $45^{0}$ & 0.6830 & 1.6879 & 1.6675 \\
0.1 & 0.1 & 7.0 & 5.0 & 0.1 & 1.0 & $\mathbf{0 . 5}$ & 0.9 & 0.1 & 0.1 & 0.5 & $45^{0}$ & 0.6716 & 1.6369 & 0.8096 \\
0.1 & 0.1 & 7.0 & 5.0 & 0.1 & 1.0 & 0.1 & $\mathbf{2 . 0}$ & 0.1 & 0.1 & 0.5 & $45^{0}$ & 0.6774 & 1.6550 & 0.5960 \\
0.1 & 0.1 & 7.0 & 5.0 & 0.1 & 1.0 & 0.1 & 0.9 & $\mathbf{0 . 2}$ & 0.1 & 0.5 & $45^{0}$ & 0.5478 & 1.7375 & 0.9107 \\
0.1 & 0.1 & 7.0 & 5.0 & 0.1 & 1.0 & 0.1 & 0.9 & 0.1 & $\mathbf{0 . 2}$ & 0.5 & $45^{0}$ & -0.1503 & 1.9520 & 0.9602 \\
0.1 & 0.1 & 7.0 & 5.0 & 0.1 & 1.0 & 0.1 & 0.9 & 0.1 & 0.1 & $\mathbf{1 . 0}$ & $45^{0}$ & 0.6609 & 1.6037 & 1.1812 \\
0.1 & 0.1 & 7.0 & 5.0 & 0.1 & 1.0 & 0.1 & 0.9 & 0.1 & 0.1 & 0.5 & $\mathbf{9 0}$ & 0.6574 & 1.5927 & 1.3004 \\
\hline
\end{tabular}

A picture of the influence of factor $M$ on the velocity sketch portrayed in Figure 2. According to Figure 2 by improving the constraint $M$, the velocity outline reduced. Physically, the magnetic field produced Lorentz force, which created resistance to the flow, by means of slowing down the speed of the liquid and the momentum boundary thinned across the boundary. The parallel outcome had gotten in the instance of angular velocity against changed values of $M$ in Figure 3 . The reason behind this is the resistive force termed as Lorentz force, which slows down the fluid speed. Whereas different impressions are presented in Figures 4 and 5 in the case of temperature and concentration sketches against $M$. Physically, the thermal and concentration boundary layer thicknesses increased by strengthening the magnetic effect.

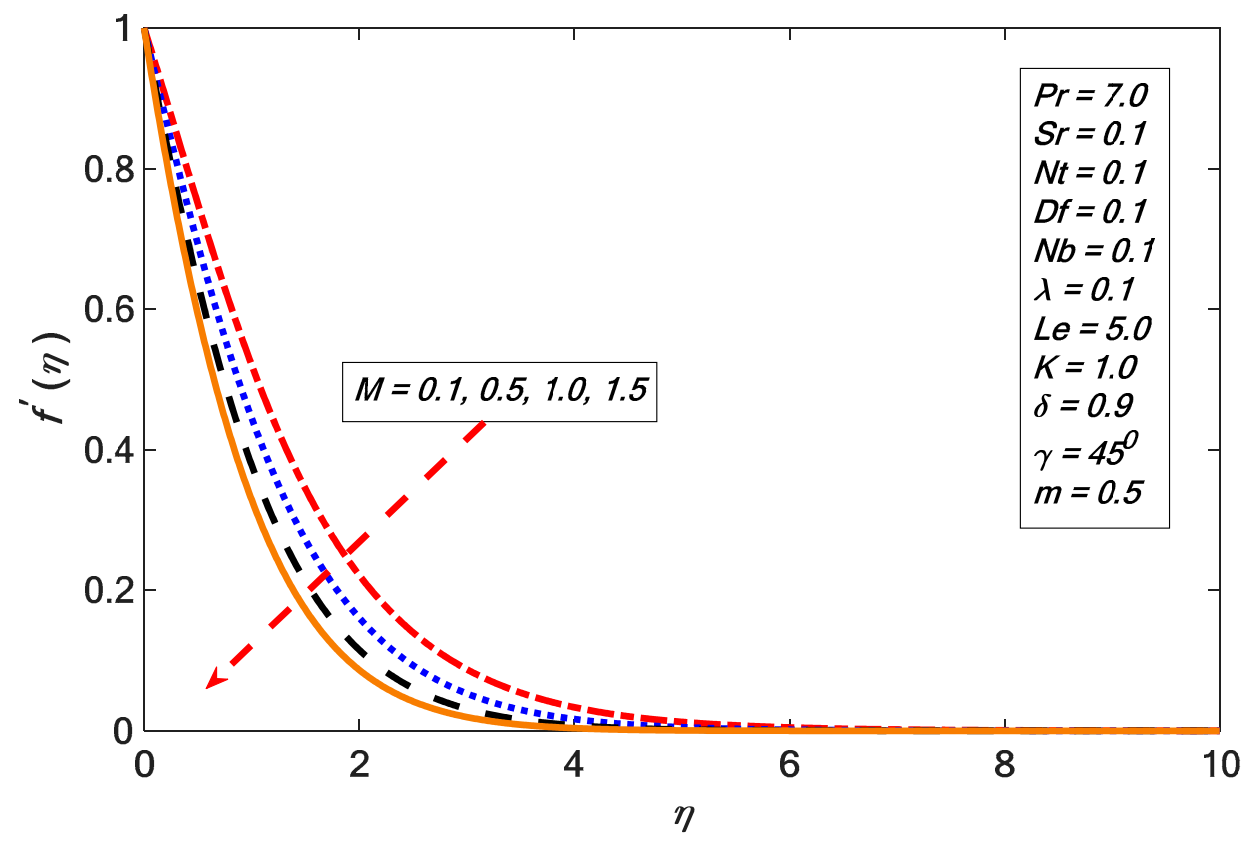

Figure 2. Variations in the velocity profile for several values of $M$. 


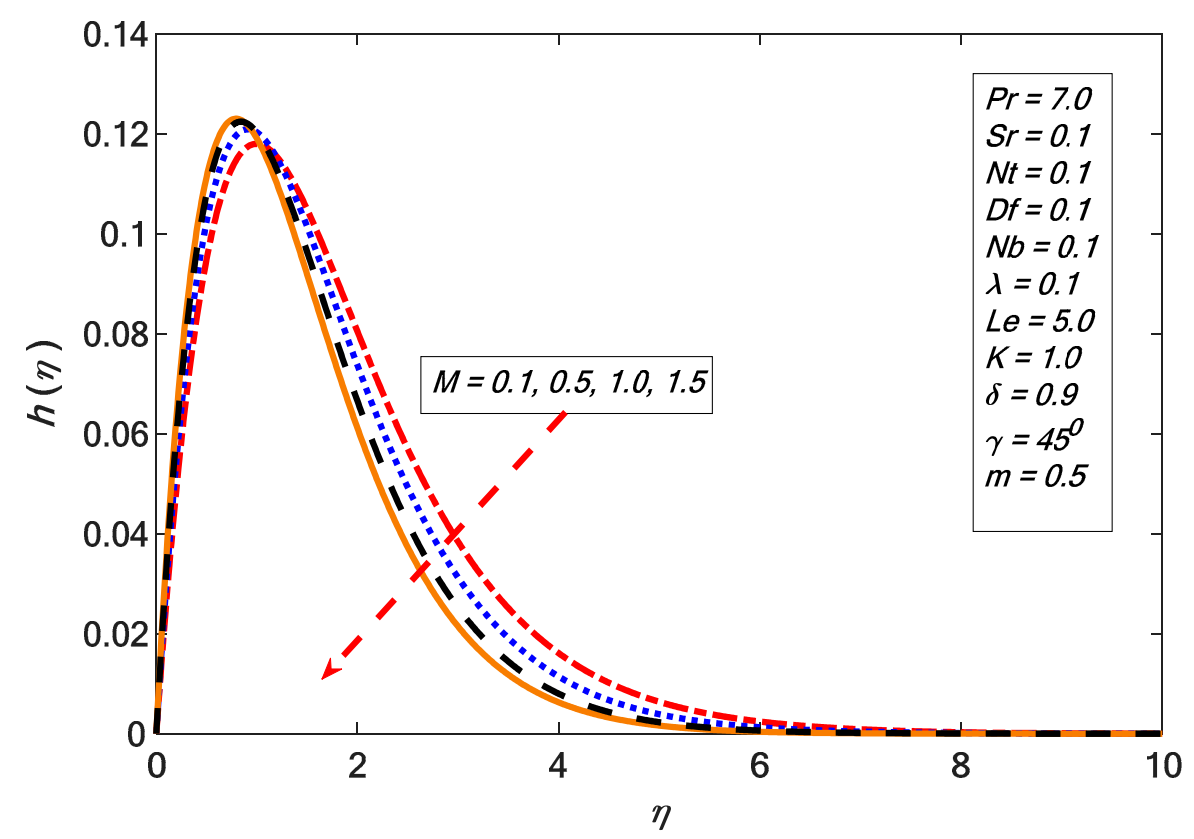

Figure 3. Variations in the angular velocity for several values of $M$.

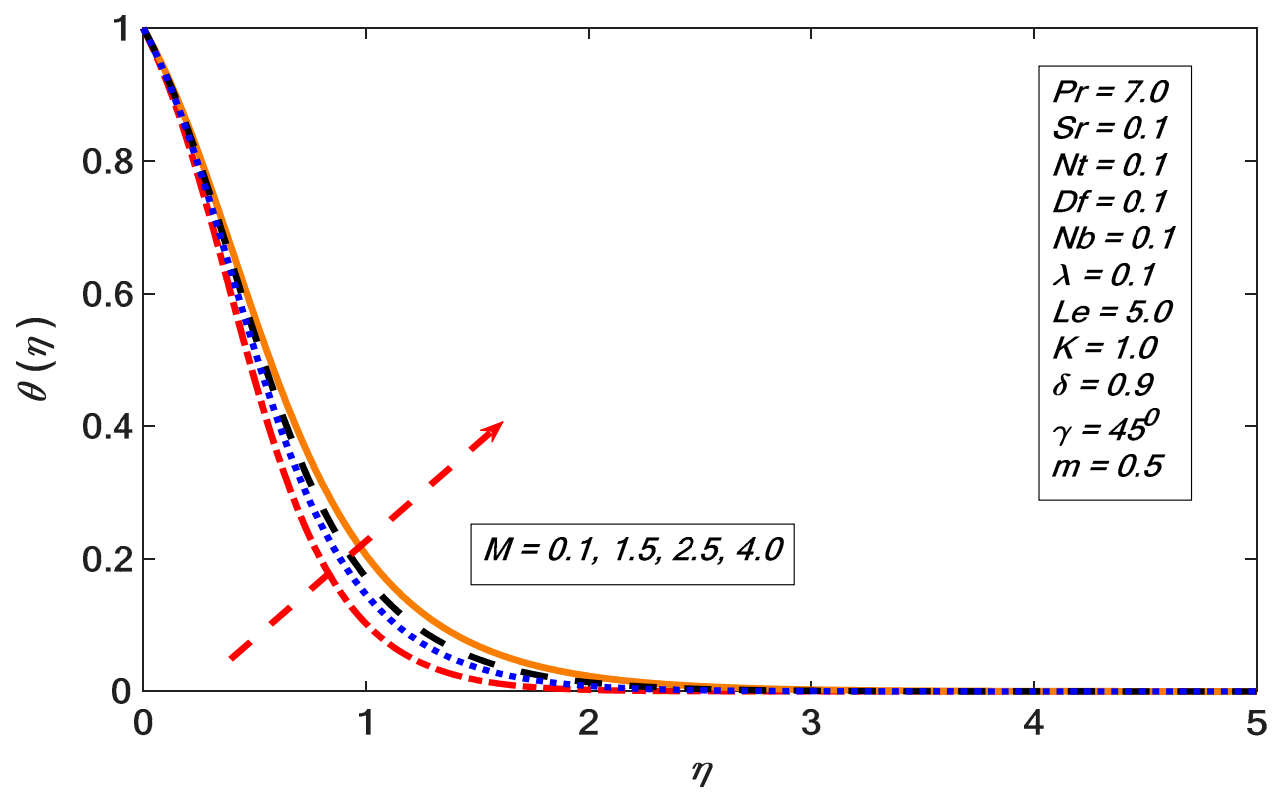

Figure 4. Variation in the temperature profile for several values of $M$. 


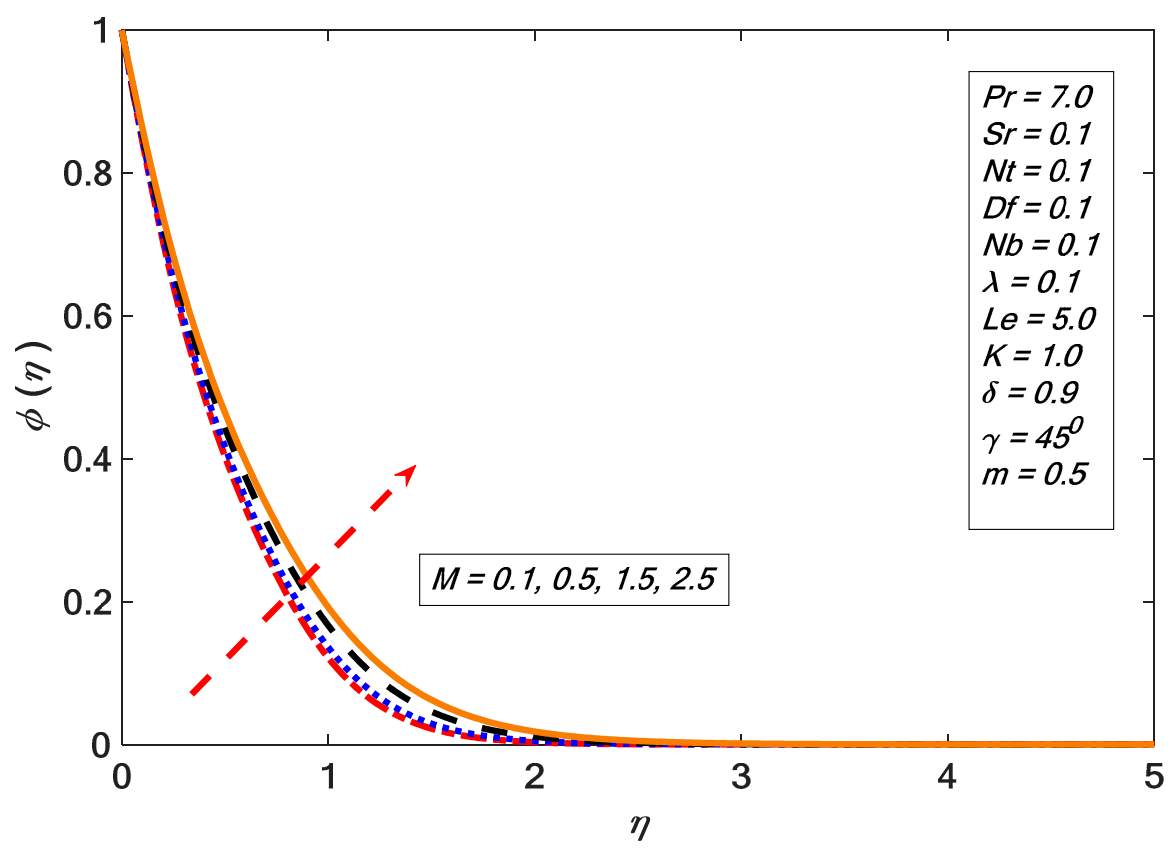

Figure 5. Variations in the concentration profile for several values of $M$.

The velocity outline shows a direct correspondence with the material factor $K$ (see Figure 6). Besides, Figure 7 points out that the angular velocity profile upsurged by the growth of $K$. Physically, viscidness of the boundary layer decreased by improving the values of $K$.

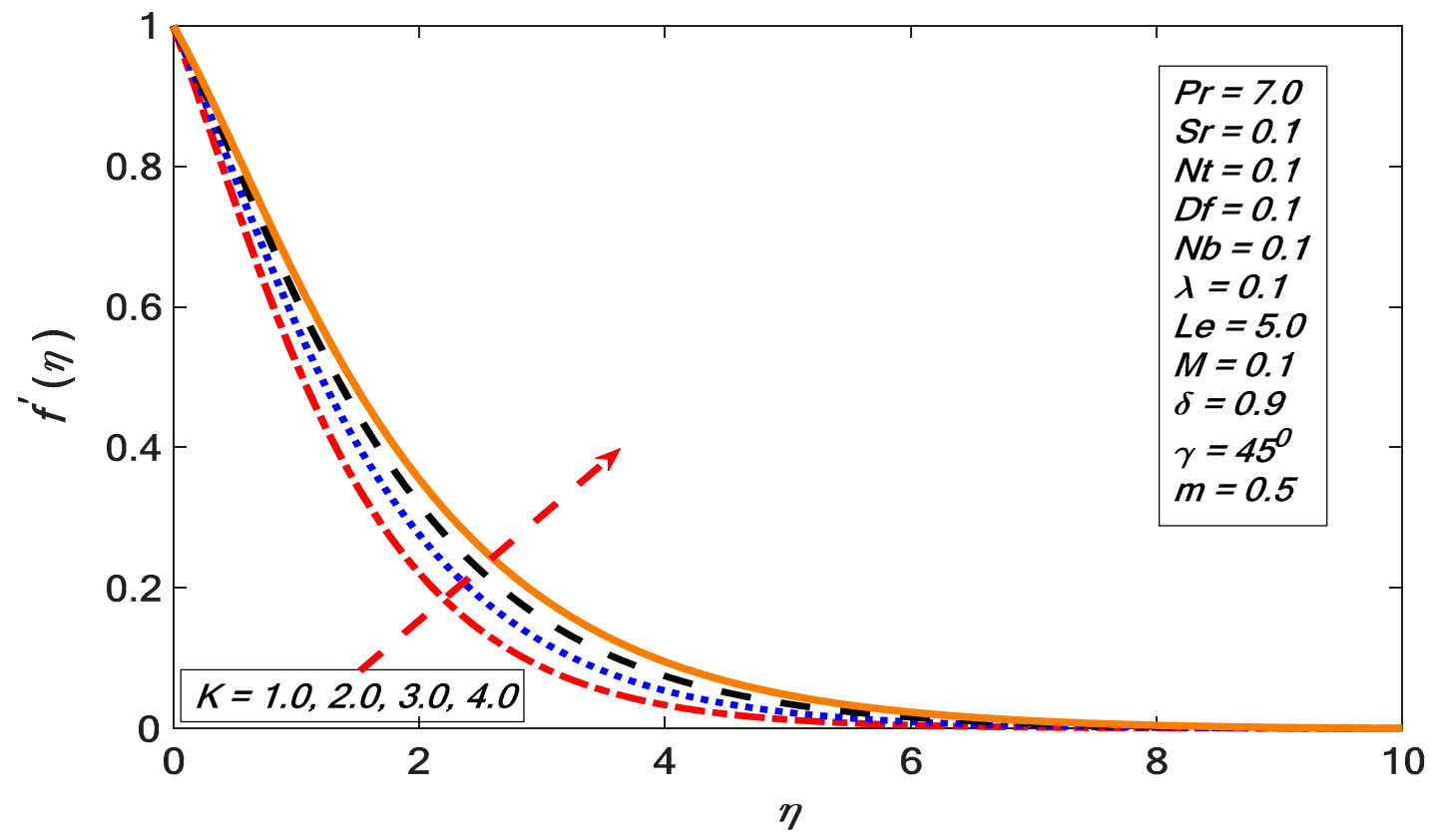

Figure 6. Variations in the velocity profile for several values of $K$. 


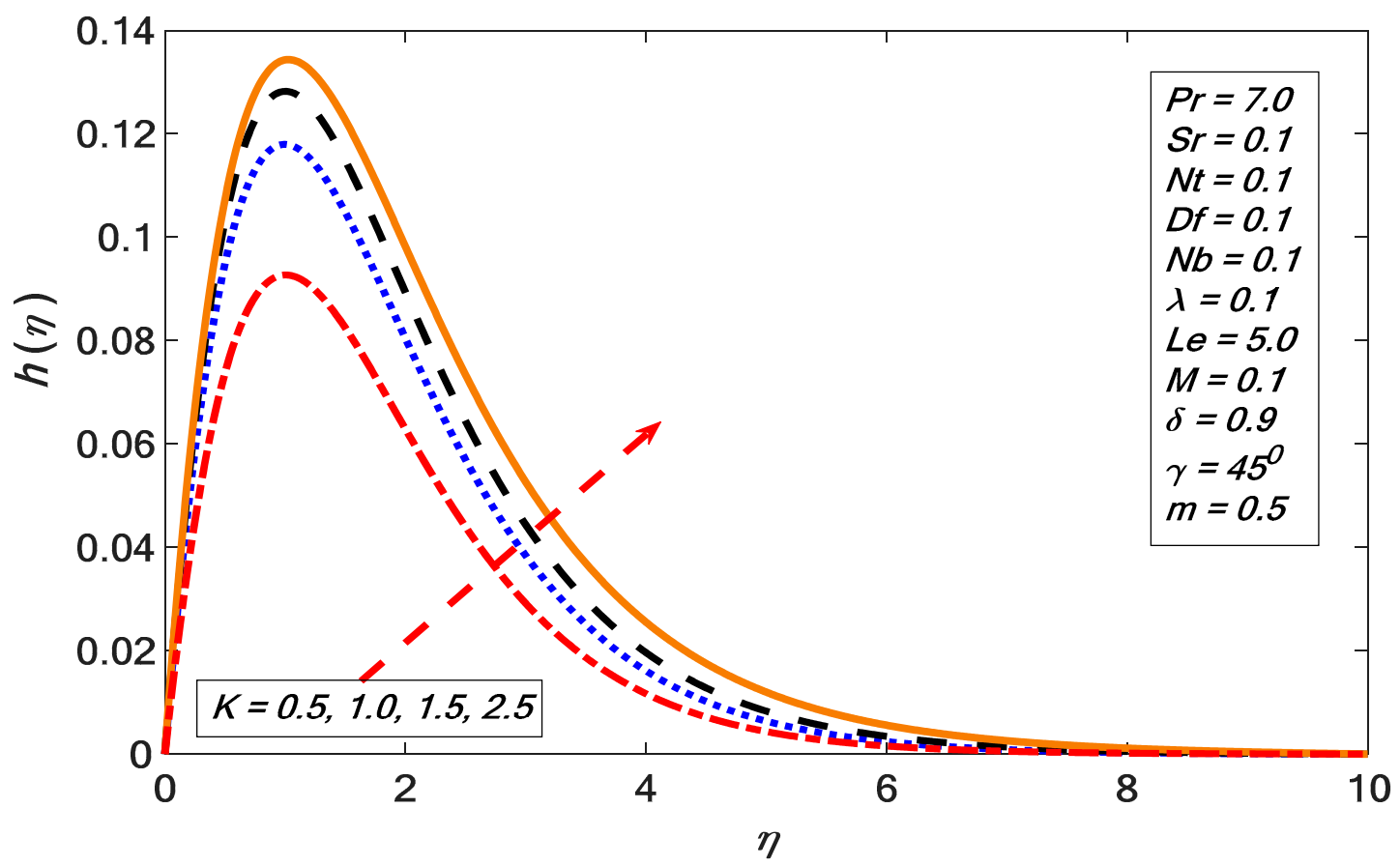

Figure 7. Variations in the angular velocity profile for several values of $K$.

Figure 8 interprets the significance of the inclination factor $\gamma$ on the velocity outline. It is perceived from Figure 8 the velocity outline ran down by enhancing the values of $\gamma$. Moreover, the circumstances indicate that the maximum gravitational force acted on flow in the case of $\gamma=0$ because, in this state, the sheet would be vertical. On the other hand, for $\gamma=90^{\circ}$ the sheet would be horizontal, which causes a decline in velocity profile as the power of the bouncy forces drop. Besides, the opposite results recovered in Figures 9 and 10 for larger values of $\gamma$ in the order of temperature and concentration sketches.

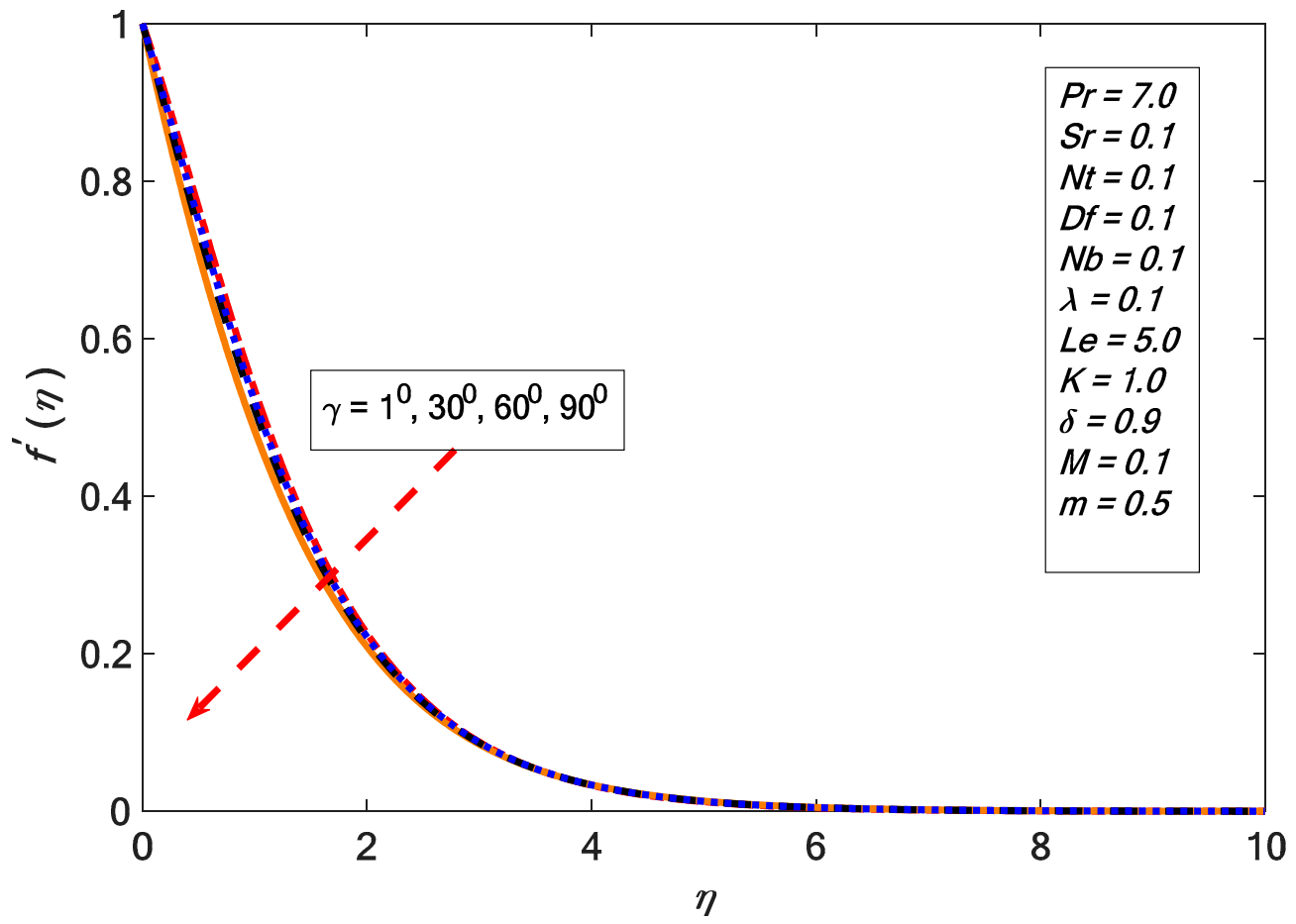

Figure 8. Variations in the velocity profile for several values of $\gamma$. 


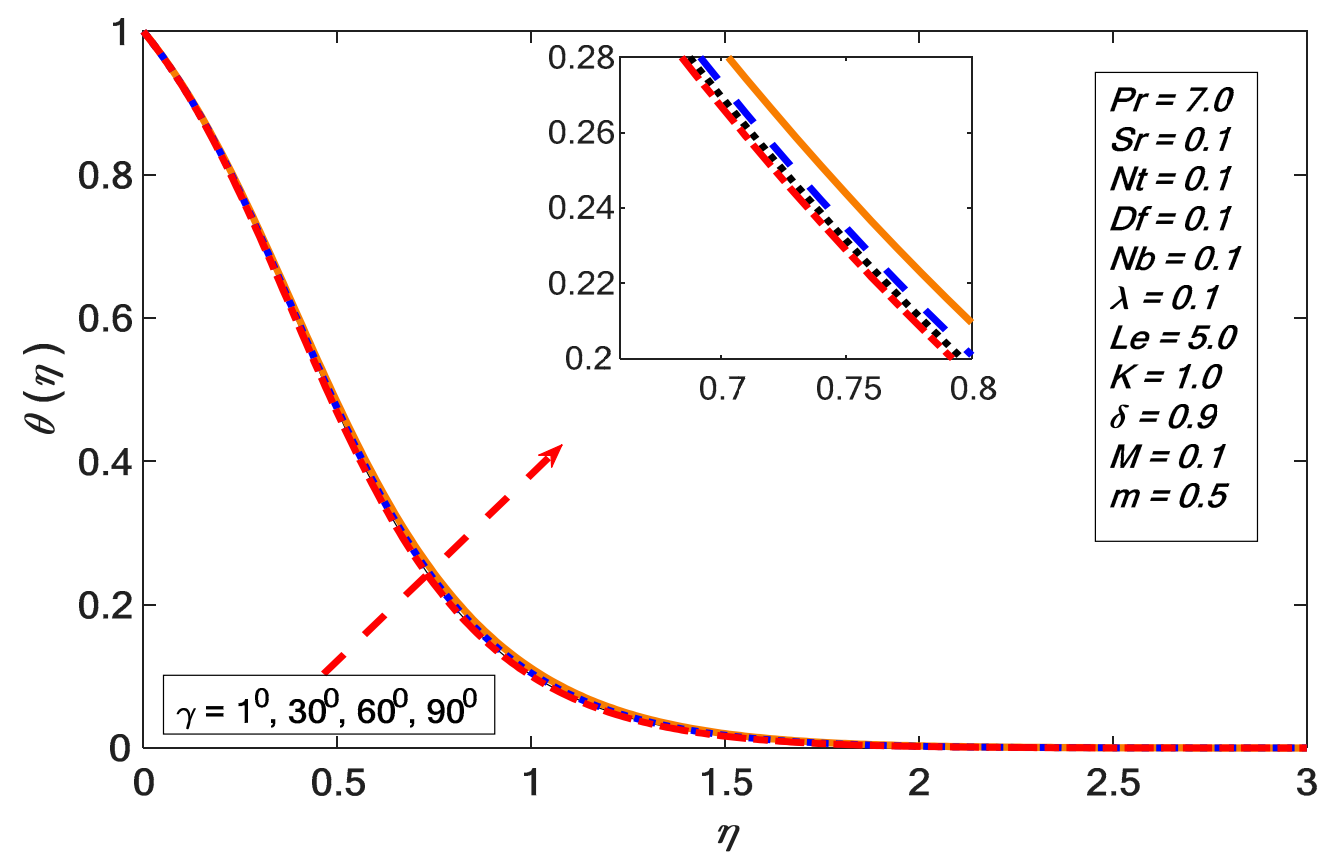

Figure 9. Variations in the temperature profile for several values of $\gamma$.

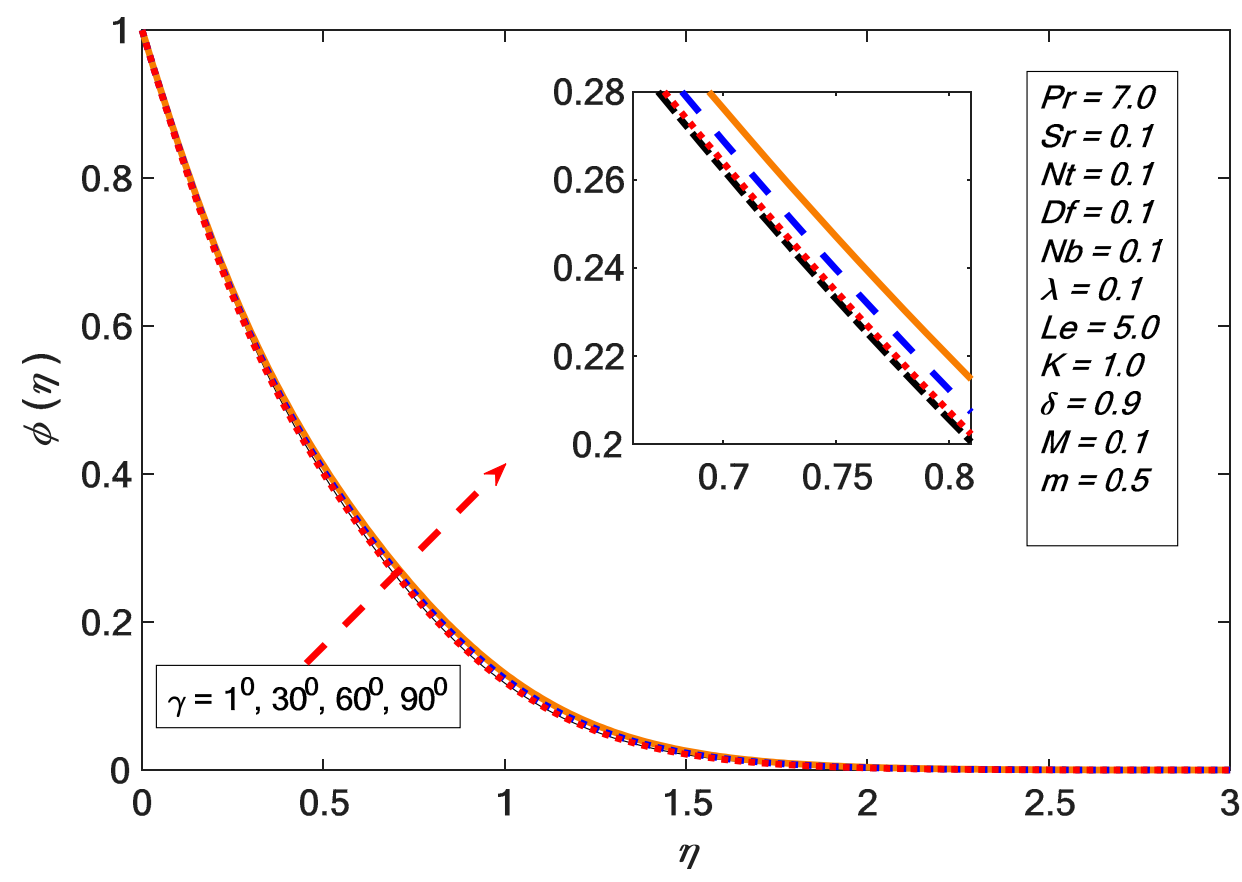

Figure 10. Variations in the concentration profile for several values of $\gamma$.

The impact of $\lambda$ on velocity contour is exhibited in Figure 11. Figure 11 demonstrates that the velocity profile increased by increasing the buoyancy force factor $\lambda$. Physically, the rise in the buoyancy force reasoned the lessening viscous force due to which the fluid particles moved quicker. In summary, the enhancement in the buoyancy force tended to enhance the velocity profile. On the other hand, in Figure 12 the temperature profile decreased by improving $\lambda$ and similar effect prominent in the case of the concentration profile shown in Figure 13. 


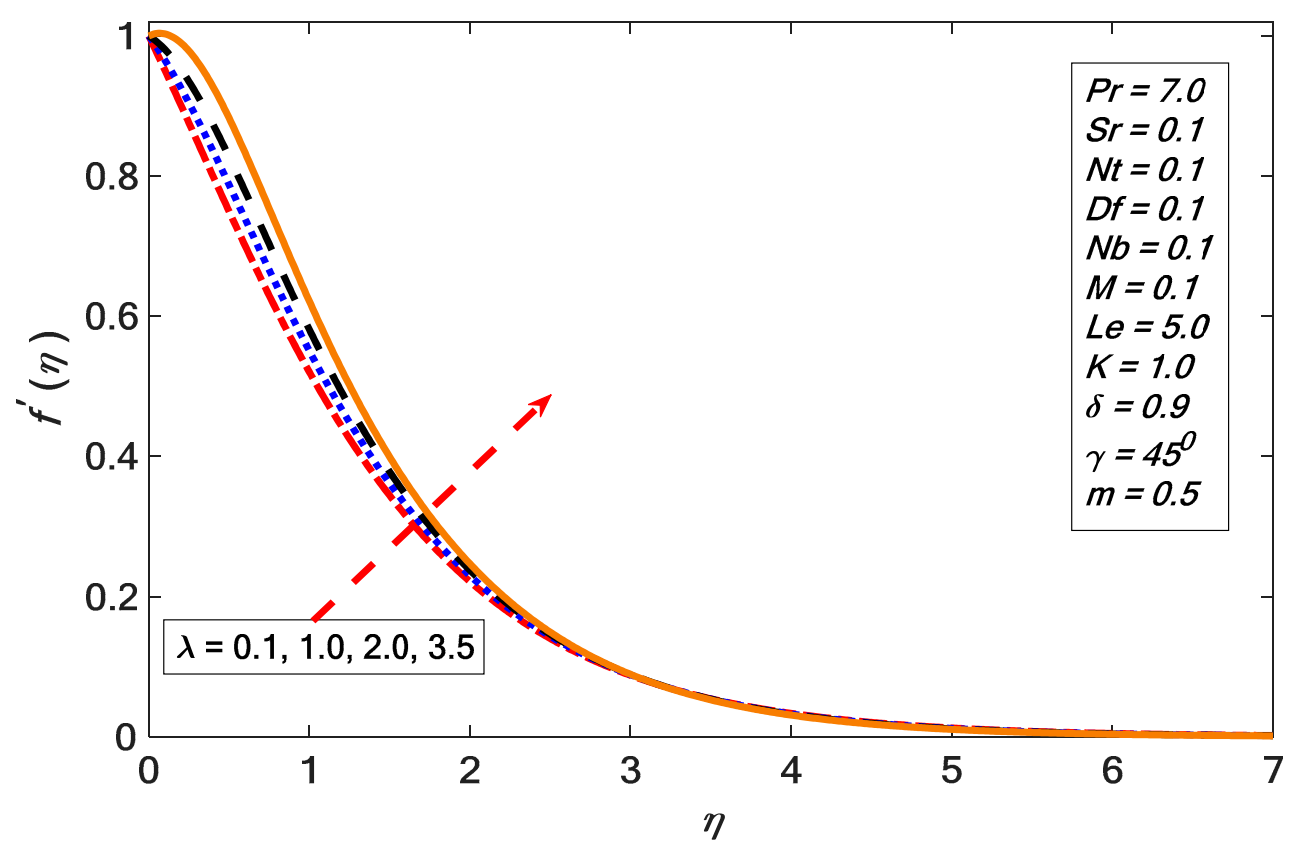

Figure 11. Variations in the velocity profile for several values of $\lambda$.

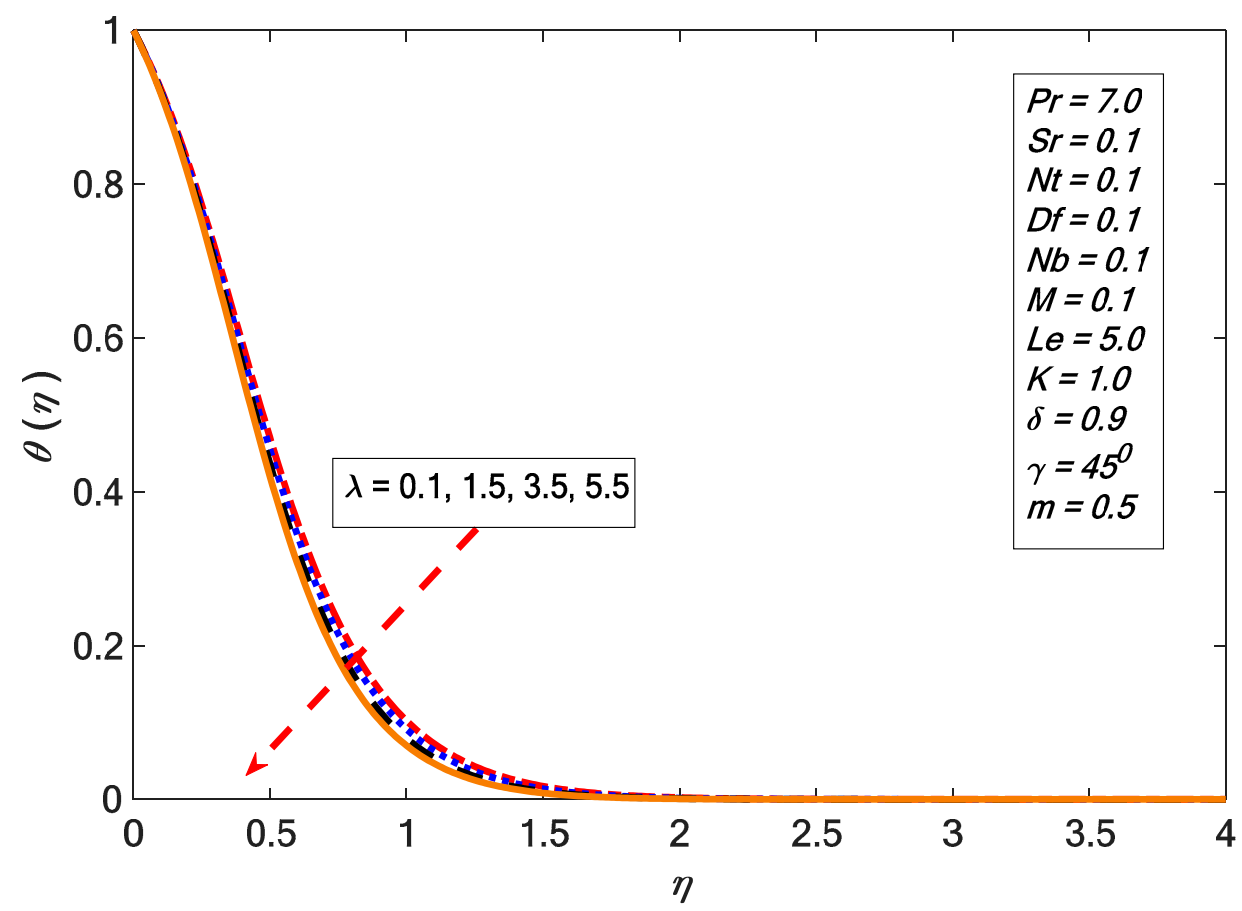

Figure 12. Variations in the temperature profile for several values of $\lambda$. 


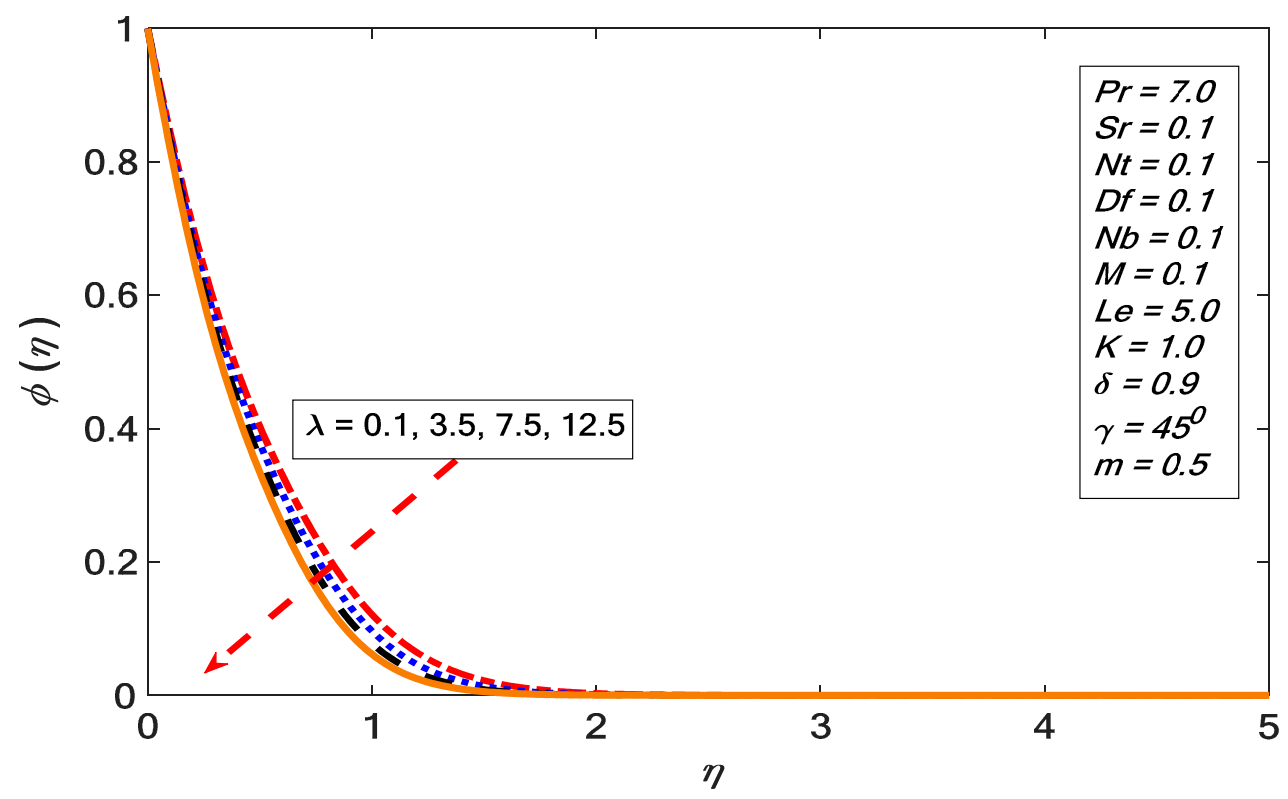

Figure 13. Variations in the concentration profile for several values of $\lambda$.

Figures 14-16 portrayed the effect of $\delta$ on velocity, temperature, and concentration contours. It is noted from Figure 14, the velocity profile upturned by enhancing the constraint $\delta$. Figure 14 reveals the effect the solutal buoyancy impact on the velocity profile. The concentration difference, length, and viscosity of the fluid affected the solutal buoyancy parameter. Therefore, as we enhanced the solutal buoyancy parameter, the viscosity declined and the concentration increased due to which the velocity of the fluid increased. Whereas the opposite impact (falls) was shown for temperature and concentration contours against large values of $\delta$ shown in Figures 15 and 16.

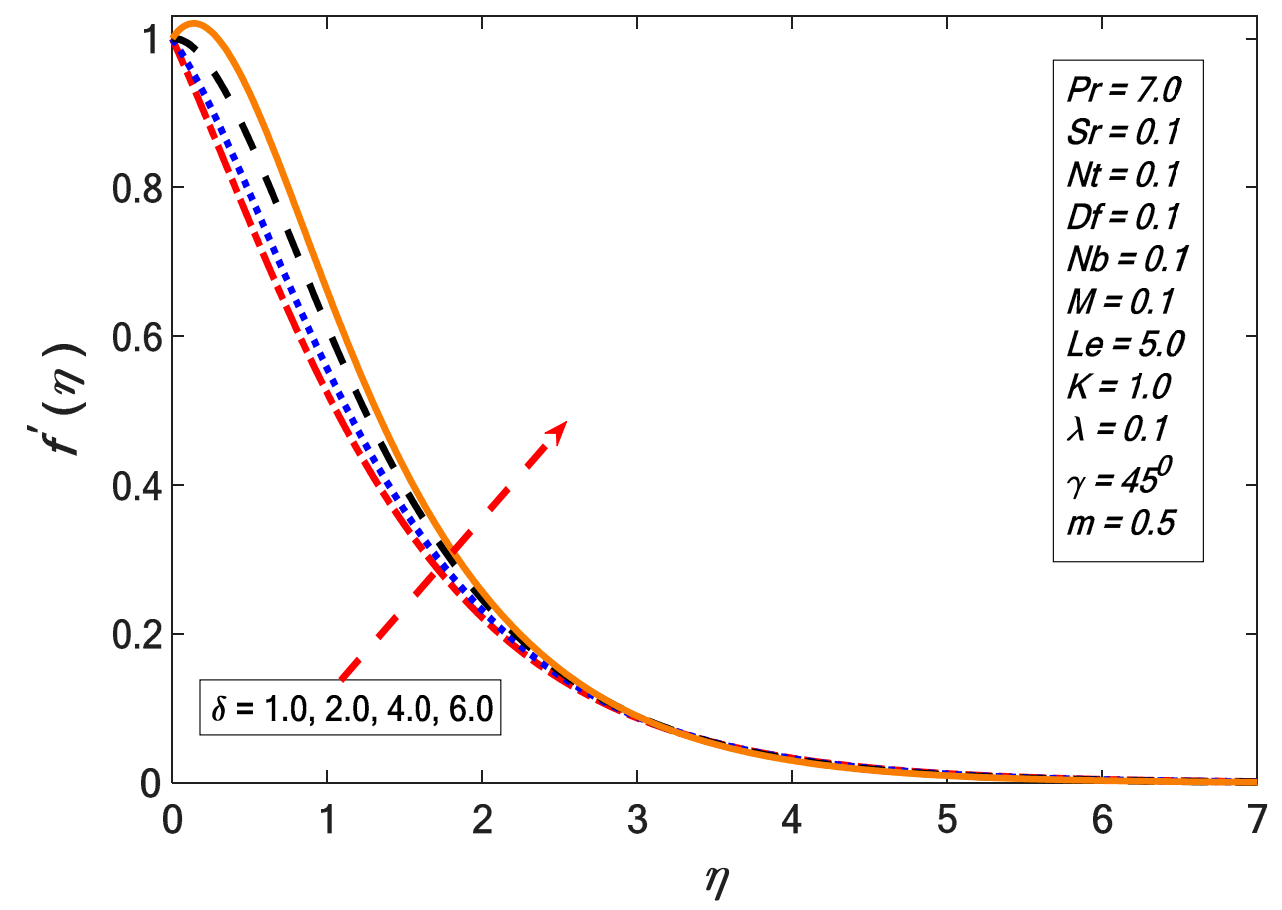

Figure 14. Variations in the velocity profile for several values of $\delta$. 


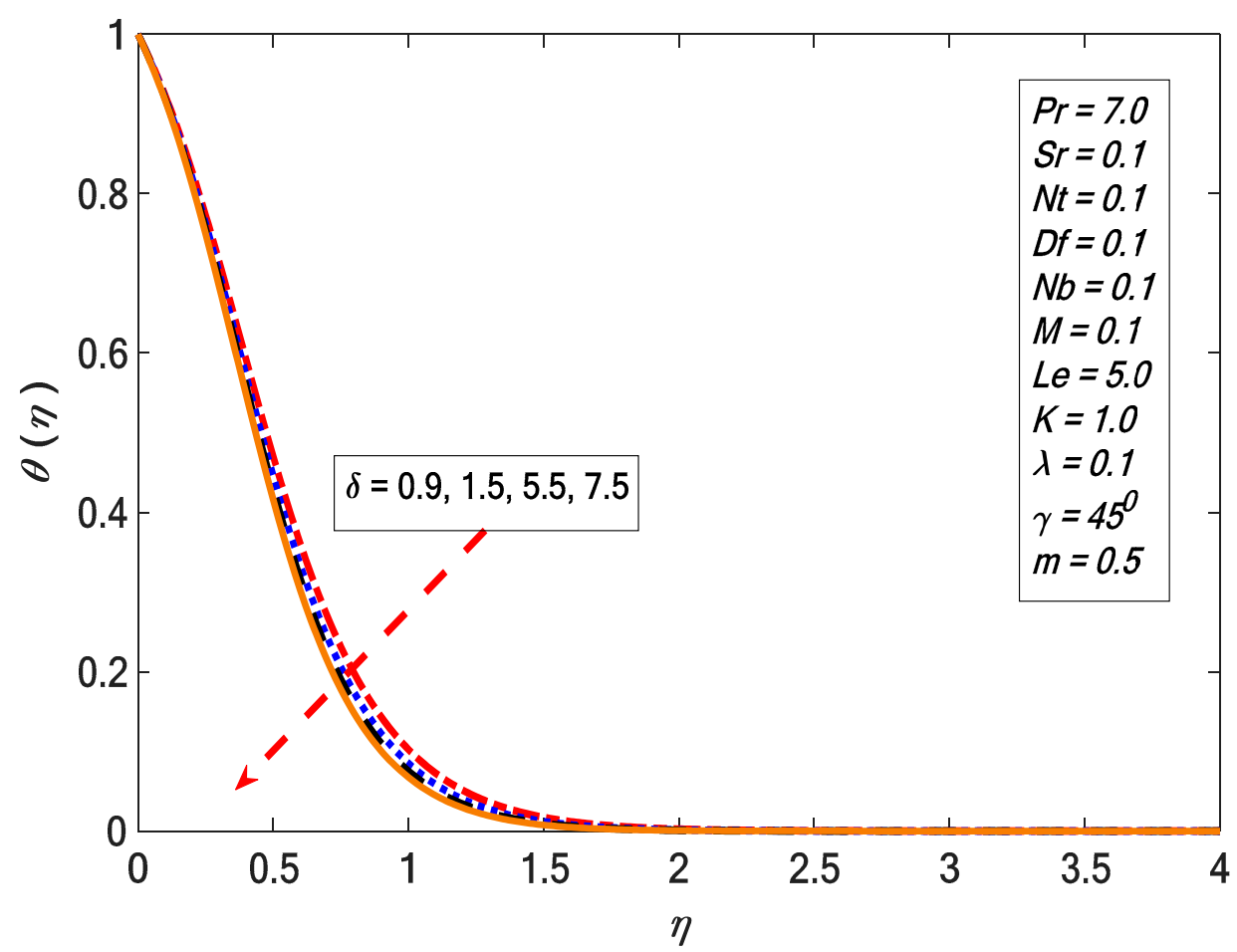

Figure 15. Variations in the temperature profile for several values of $\delta$.

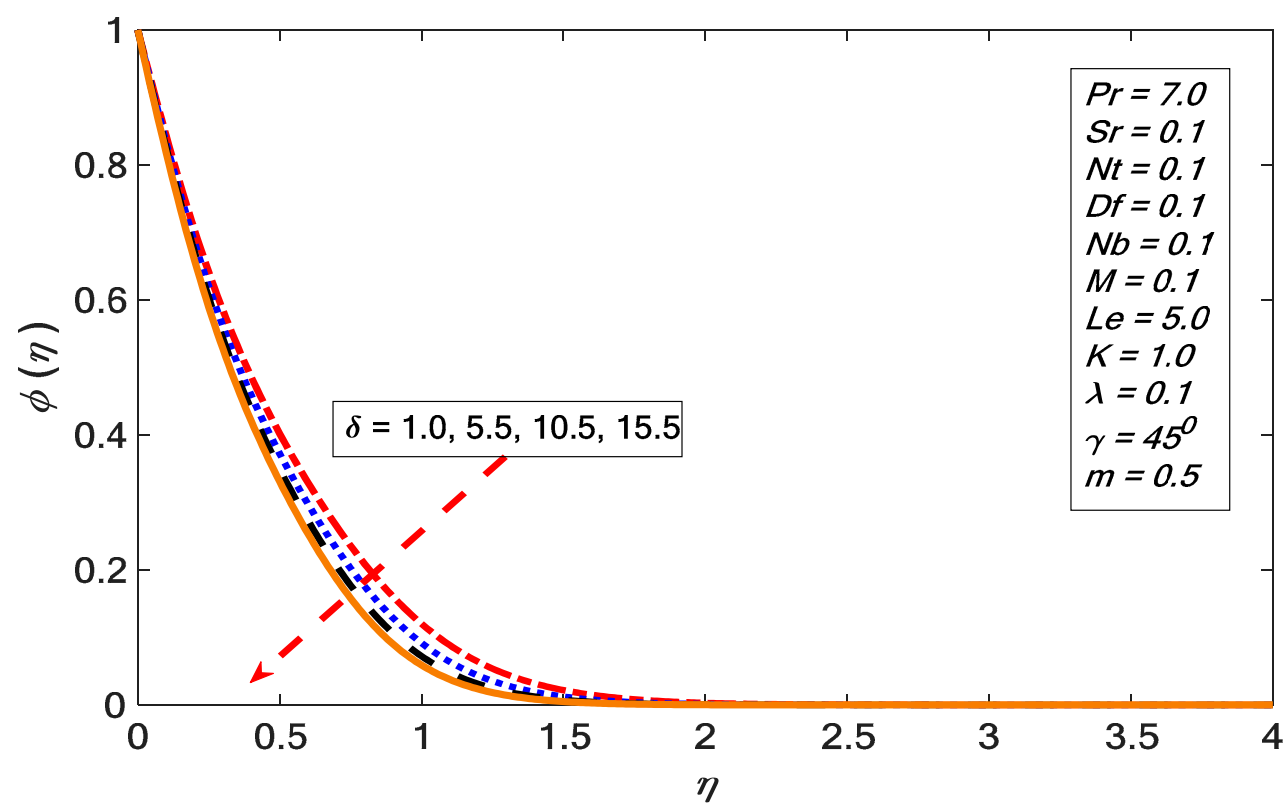

Figure 16. Variations in the concentration profile for several values of $\delta$.

The velocity profile decreased for higher values $m$ of depicts in Figure 17. It is observed that the velocity field was not much different in the case of a linear or nonlinear stretching sheet as an associate to the uniformly moving surface. Physically, the momentum boundary layer thickness reduced with the growth of the nonlinear stretching parameter. Moreover, temperature and concentration outlined an increase for large values of $m$ present in Figures 18 and 19, respectively. Figures 20 and 21 show the effect of Brownian motion on the temperature and concentration profiles, respectively. The temperature sketch enlarged on improving $N b$, whereas concentration distribution shows the opposite behavior. Physically, the boundary layer heated up due to the development in Brownian motion, which inclined 
to travel nanoparticles from the extending sheet to the motionless liquid. Therefore, the absorption nanoparticle lessened.

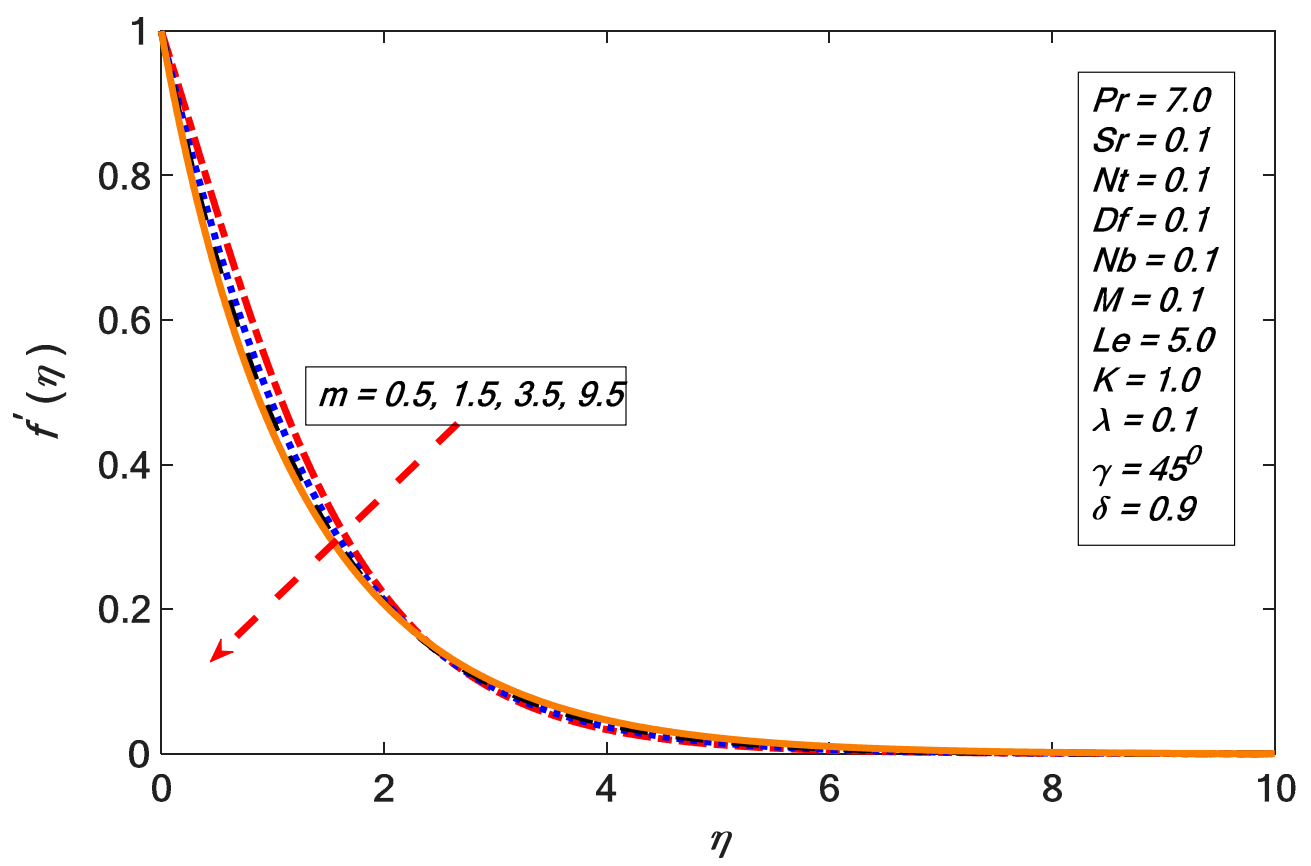

Figure 17. Variations in the velocity profile for several values of $m$.

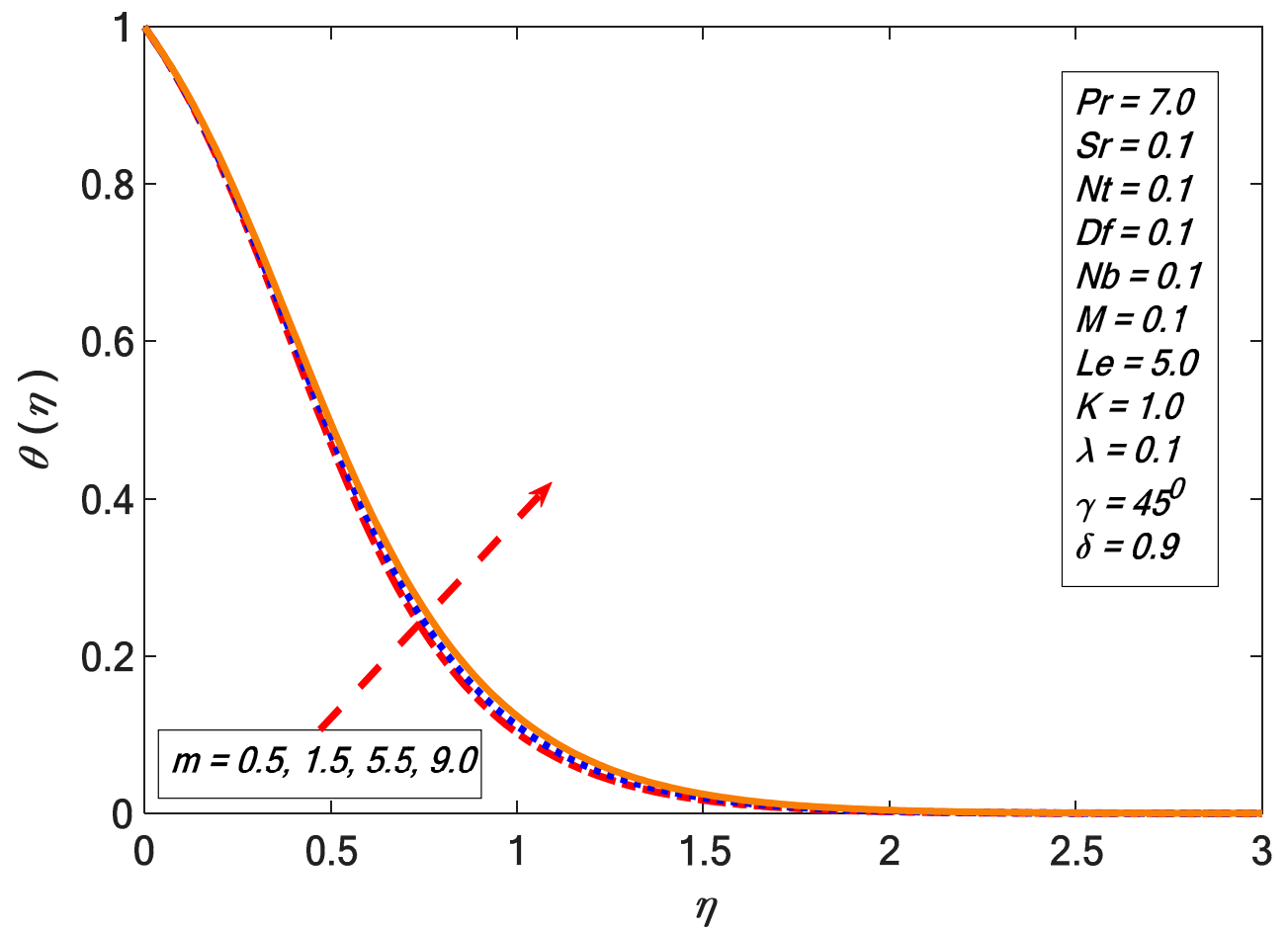

Figure 18. Variations in the temperature profile for several values of $m$. 


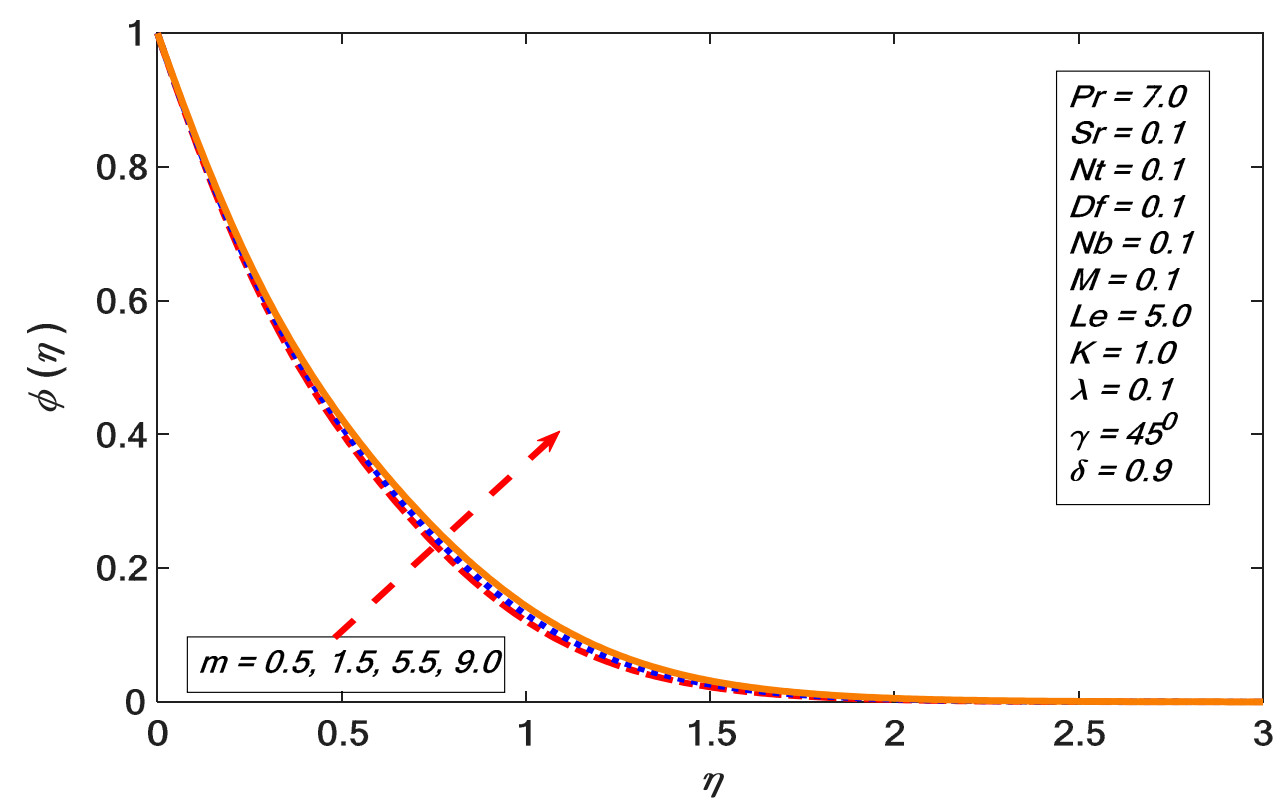

Figure 19. Variations in the concentration profile for several values of $m$.

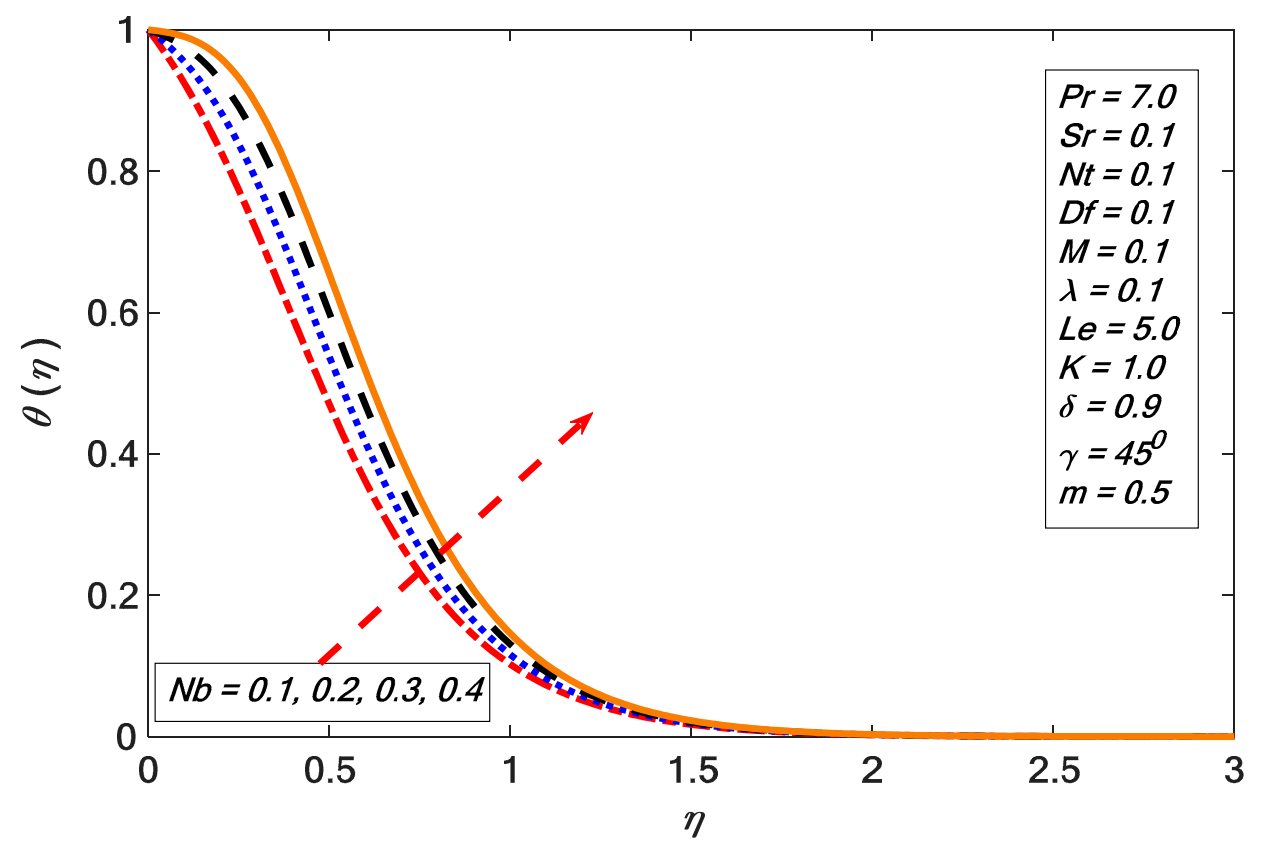

Figure 20. Variations in the temperature profile for several values of $\mathrm{Nb}$. 


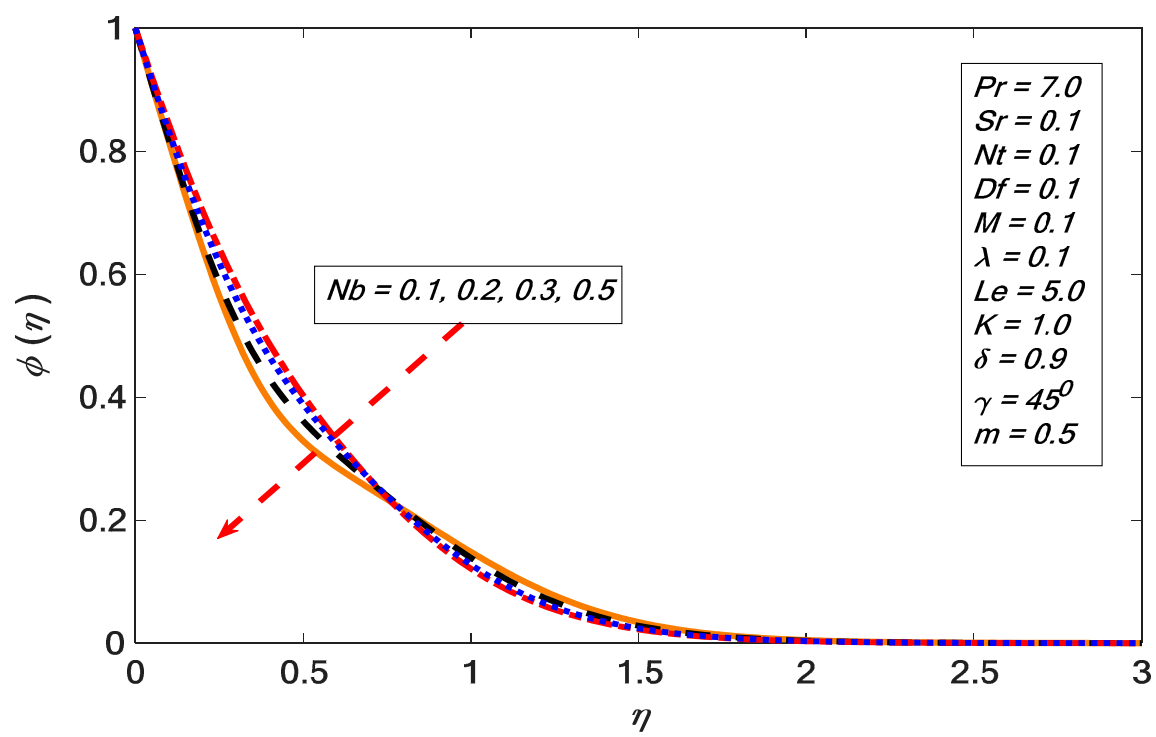

Figure 21. Variations in the concentration profile for several values of $\mathrm{Nb}$.

Figures 22 and 23 present temperature and concentration profiles for altered values of thermophoresis parameters $N t$. It is perceived that both temperature and concentration contours upsurged by growing the thermophoresis parameter. Thermophoresis works to warm the boundary layer for small values of Prandtl number and Lewis number. Therefore we could infer that the amount of heat and mass exchange was reduced by improving the thermophoresis parameter Nt. Figure 24 reveals that by growing the values of the Prandtl number parameter, Pr the temperature profile dropped because the thermal boundary layer viscosity declined by increasing the Prandtl number Pr. In short, an upturn in Prandtl number Pr means the deliberate amount of thermal dispersion. Figure 25 displays the result of Lewis number Le on the concentration profile. The boundary layer viscosity was decreasing by improving the values of Lewis number $L e$.

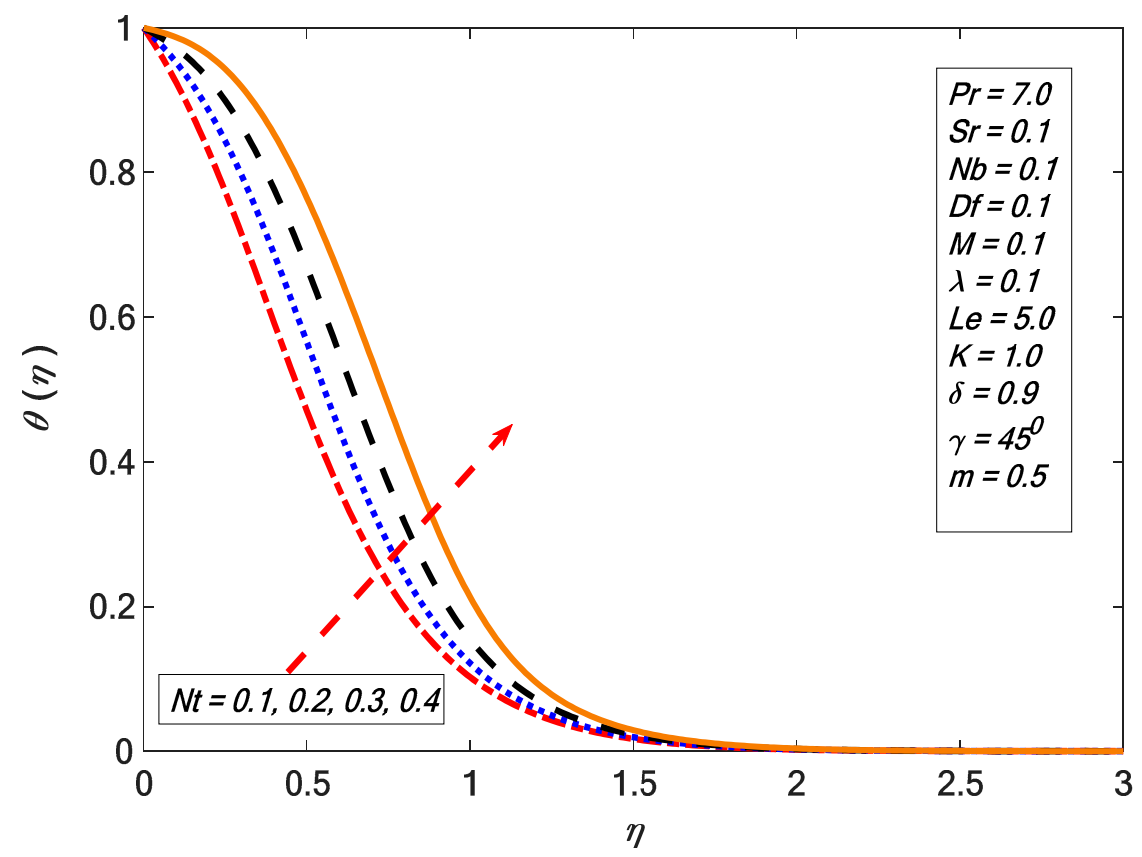

Figure 22. Variations in the temperature profile for several values of $\mathrm{Nt}$. 


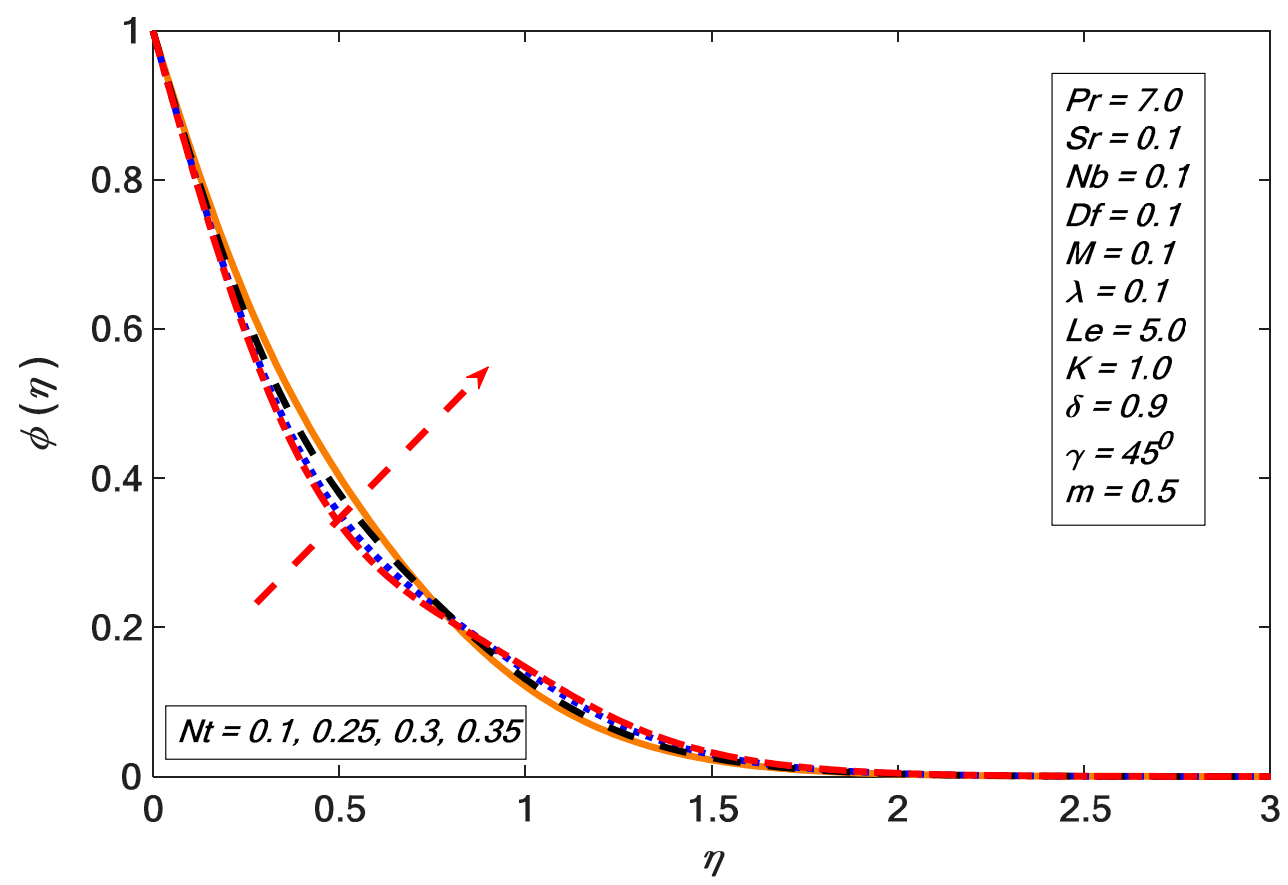

Figure 23. Variations in the concentration profile for several values of $\mathrm{Nt}$.

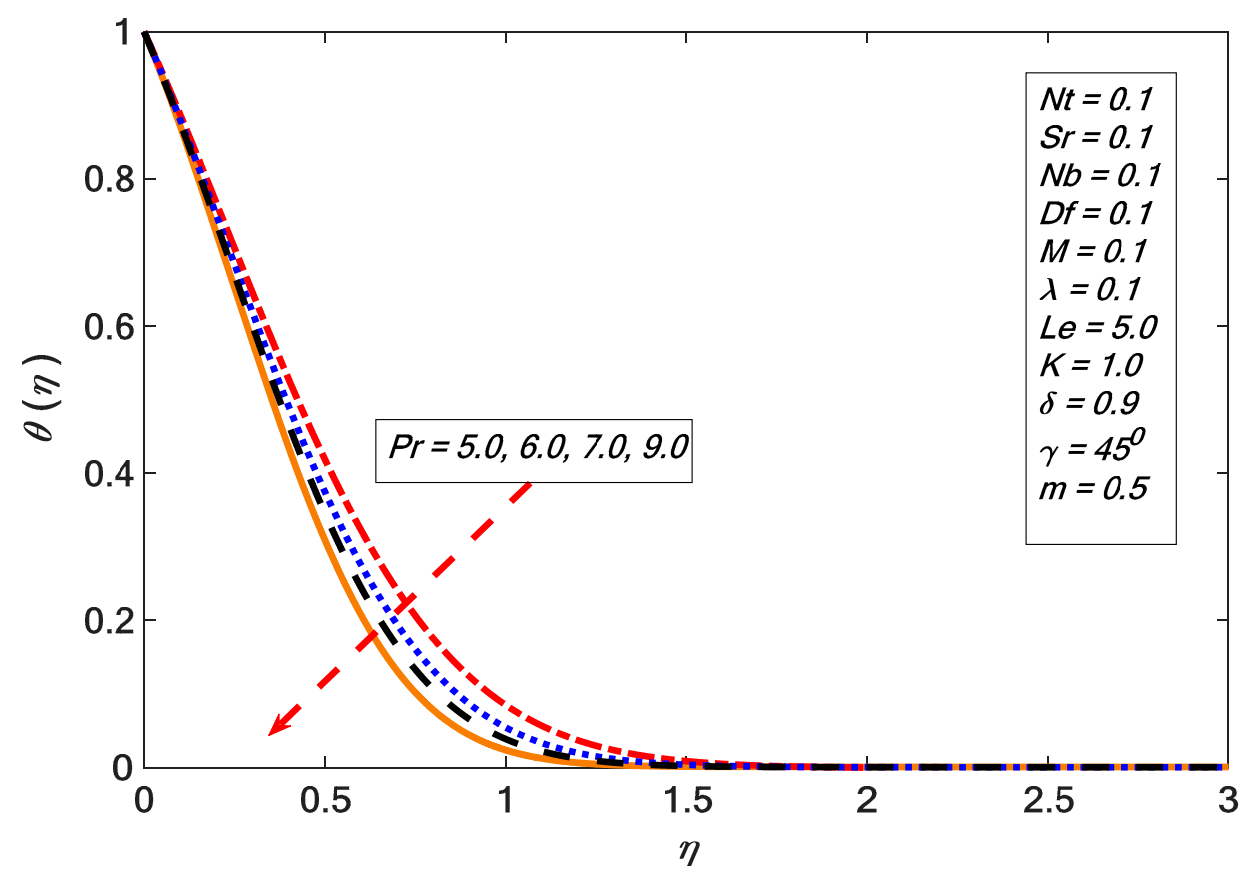

Figure 24. Variations in the temperature profile for several values of Pr. 


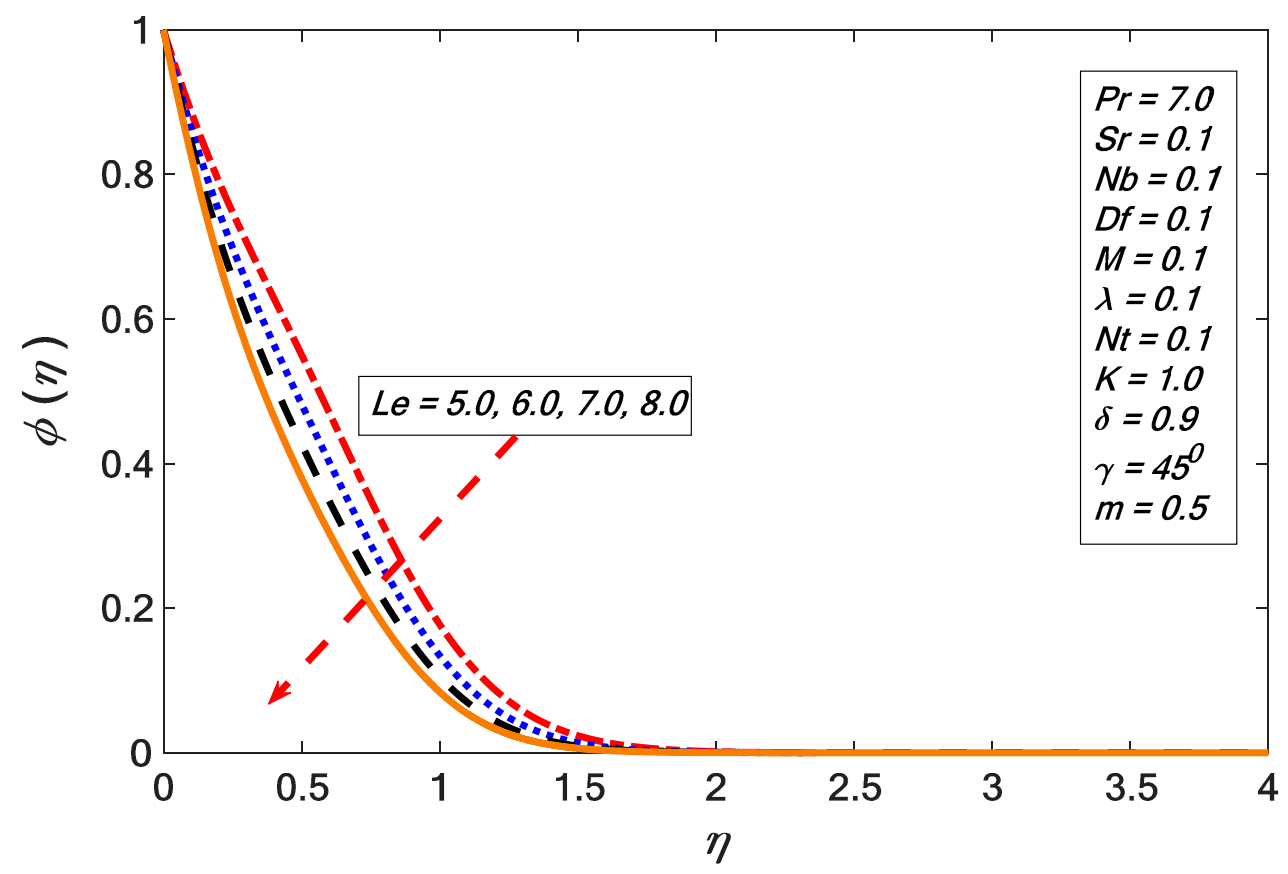

Figure 25. Variations in the concentration profile for several values of $L e$.

Figure 26 shows that the temperature profile became large for larger values in the parameter $D f$. It can be justified as an increase in the Dufour parameter caused an increase in the concentration gradient resulting in mass diffusion taking place more rapidly. In this way, the rate of energy transfer related to the particles became higher. That is why the temperature profile was enhanced. The impacts of Soret number on the concentration profile were observed opposite to the effect of Dufour number on the temperature profile. As the parameter Sr increased, concentration profiles reduced as displayed in Figure 27.

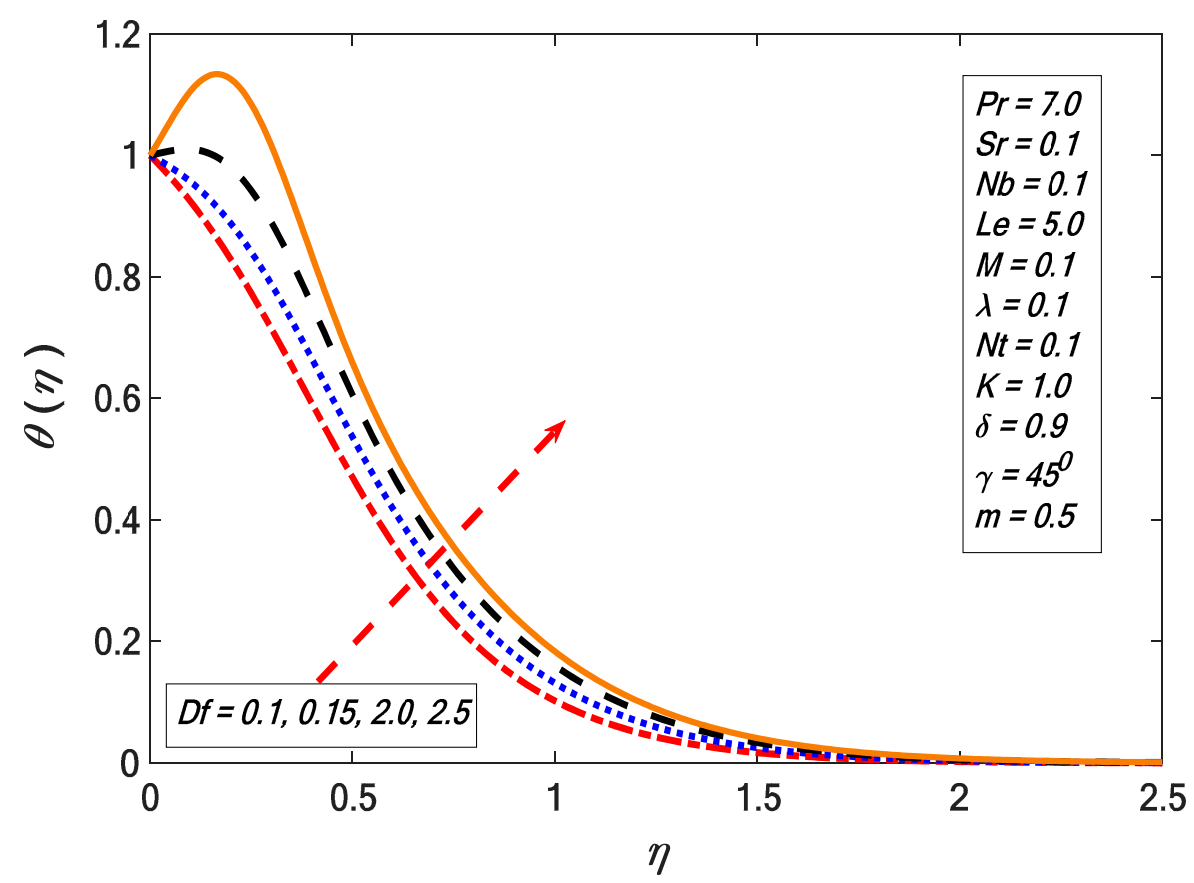

Figure 26. Variations in the temperature profile for several values of $D f$. 


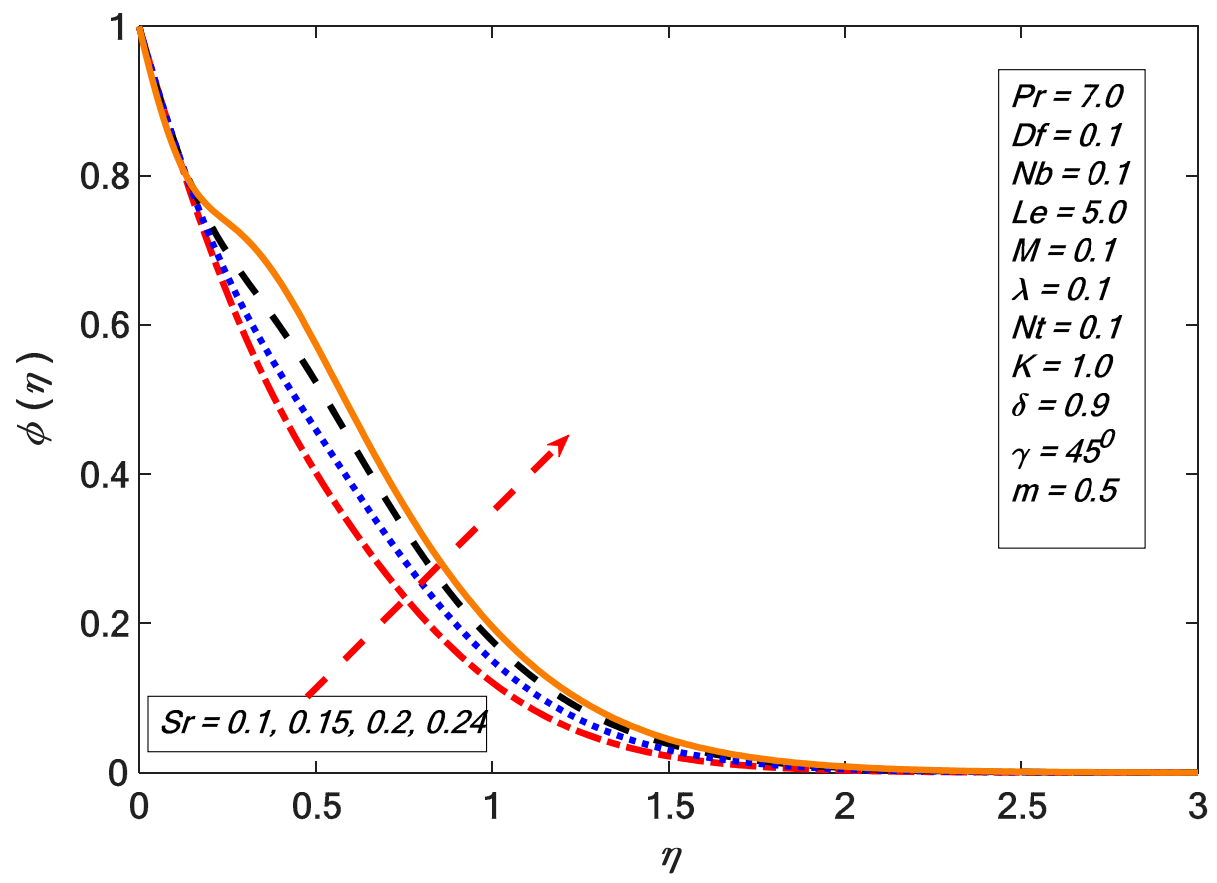

Figure 27. Variations in the concentration profile for several values of $S r$.

\section{Conclusions}

This study explored the heat and mass exchange of micropolar nanofluid flow over a nonlinear inclined extending sheet. The Soret and Dufour effects were taken into account. For numerical simulation, the Keller-box scheme was utilized. For the validity of the statistical outcomes of the current problem, Table 1 was prepared. The Brownian motion and thermophoretic impact on the temperature and concentration distributions were drawn by graphs. More exactly, this part of the research had significant uses in biomedicine, hot rolling, nuclear reactors, electronics, and glass fiber. The primary outcomes of our study were:

$>$ The skin friction was enhanced by enhancing the Dufour effects and decreased for large values of Soret effects.

$>$ The Sherwood number increased as we enhanced the Soret and Dufour effects.

$>$ The Nusselt number declined for increasing the Soret and Dufour effects.

$>$ The temperature profile was enhanced by increasing the Dufour effects.

$>$ The concentration profile decreased by enhancing the Soret effect.

$>$ The velocity profile decreased with the growth of the nonlinear stretching factor.

Author Contributions: Formulation done by K.R. and M.M. Problem solved by K.R. and M.I.A. Results computed by K.R.; I.K. and A.H.S. Results discussed by E.-S.M.S. and K.S.N. All authors contributed equally in writing manuscript.

Funding: This research was funded by Researchers Supporting Project number (RSP-2019/33), King Saud University, Riyadh, Saudi Arabia.

Acknowledgments: Researchers Supporting Project number (RSP-2019/33), King Saud University, Riyadh, Saudi Arabia.

Conflicts of Interest: The authors declare no conflict of interest. 


\section{Nomenclature}

\begin{tabular}{|c|c|c|c|c|c|}
\hline C & Fluid concentration & Sr & Soret effect parameter & $D f$ & Dufour effect parameter \\
\hline$C_{f}$ & Skin friction coefficient & $a$ & Stretching rate & $\operatorname{Re}_{x}$ & Reynolds number \\
\hline$C_{\infty}$ & $\begin{array}{l}\text { Ambient nanoparticle } \\
\text { volume fraction }\end{array}$ & Le & Lewis number & Sh & Sherwood number \\
\hline$C_{w}$ & Surface volume fraction & $\mathrm{Nb}$ & Brownian motion parameter & $T$ & Fluid temperature \\
\hline$c_{p}$ & $\begin{array}{l}\text { Specific heat at constant } \\
\text { pressure }\end{array}$ & $N t$ & Thermophoretic parameter & $T_{w}$ & Wall temperature \\
\hline$D_{B}$ & $\begin{array}{l}\text { Brownian diffusion } \\
\text { coefficient }\end{array}$ & $N u$ & Nusselt number & $T_{\infty}$ & Ambient temperature \\
\hline$D_{T}$ & $\begin{array}{l}\text { Thermophoretic diffusion } \\
\text { coefficient }\end{array}$ & $\operatorname{Pr}$ & Prandtl number & $u_{w}$ & Wall velocity \\
\hline$f$ & $\begin{array}{l}\text { Similarity function for } \\
\text { velocity }\end{array}$ & $g$ & Gravitational acceleration & $u_{\infty}$ & Ambient velocity \\
\hline$\rho c_{p}$ & Volume heat capacity & $\mu$ & Kinematic viscosity & $v$ & Dynamic viscosity \\
\hline$\phi$ & $\begin{array}{l}\text { Dimensionless solid volume } \\
\text { fraction }\end{array}$ & $w$ & Condition at the wall & $\infty$ & Ambient condition \\
\hline$\delta$ & Solutal buoyancy parameter & $\beta_{t}$ & $\begin{array}{l}\text { Thermal expansion } \\
\text { coefficient }\end{array}$ & $\beta_{c}$ & $\begin{array}{l}\text { Concentration expansion } \\
\text { coefficient }\end{array}$ \\
\hline$\sigma$ & Electric conductivity & $\gamma^{*}$ & Spin gradient viscosity & $k_{1}^{*}$ & Vertex viscosity \\
\hline$j^{*}$ & Micro inertia per unit mass & $\gamma$ & Inclination parameter & ' & $\begin{array}{l}\text { Differentiation with respect } \\
\text { to } \eta\end{array}$ \\
\hline$u$ & Velocity in $x$ direction & $v$ & Velocity in $y$ direction & $x$ & Cartesian coordinate \\
\hline$\theta$ & Dimensionless temperature & $m$ & $\begin{array}{l}\text { Non-linear stretching } \\
\text { parameter }\end{array}$ & $k$ & Thermal conductivity \\
\hline$\rho$ & Fluid density & $\lambda$ & Bouncy parameter & $B_{0}$ & $\begin{array}{l}\text { Uniform magnetic field } \\
\text { strength }\end{array}$ \\
\hline K & Material parameter & $\eta$ & $\begin{array}{l}\text { Similarity independent } \\
\text { variable }\end{array}$ & $\alpha$ & Thermal diffusivity \\
\hline$N^{*}$ & $\begin{array}{l}\text { Non-dimensional angular } \\
\text { velocity }\end{array}$ & & & & \\
\hline
\end{tabular}

\section{References}

1. Sakiadis, B.C. Boundary-layer behavior on continuous solid surfaces: I. Boundary-layer equations for two-dimensional and axisymmetric flow. AIChE J. 1961, 7, 26-28. [CrossRef]

2. Crane, L.J. Flow past a stretching plate. Z. Angew. Math. Phys. 1970, 21, 645-647. [CrossRef]

3. Ramesh, G.K.; Gireesha, B.J.; Bagewadi, C.S. Heat transfer in MHD dusty boundary layer flow over an inclined stretching sheet with non-uniform heat source/sink. Adv. Math. Phys. 2012, 2012, 657805. [CrossRef]

4. Singh, P.K. Heat and mass transfer in MHD boundary layer flow past an inclined plate with viscous dissipation in porous medium. Int. J. Sci. Eng. Res. 2012, 3, 1-11.

5. Ali, M.; Alim, M.A.; Alam, M.S. Similarity Solution of Heat and Mass Transfer Flow over an Inclined Stretching Sheet with Viscous Dissipation and Constant Heat Flux in Presence of Magnetic Field. Procedia Eng. 2015, 105, 557-569. [CrossRef]

6. Ramesh, G.K.; Chamkha, A.J.; Gireesha, B.J. Boundary layer flow past an inclined stationary/moving flat plate with convective boundary condition. Afr. Mat. 2015. [CrossRef]

7. Malik, M.Y.; Rehman, K.U. Effects of the chemical reaction on MHD free convection dissipative fluid flow past an inclined porous surface by way of heat generation: A Lie group analysis. Inf. Sci. Lett. 2016, 5, 35-45. [CrossRef]

8. Hayat, T.; Qayyum, S.; Alsaedi, A.; Asghar, S. Radiation effects on the mixed convection flow induced by an inclined stretching cylinder with non-uniform heat source/sink. PLoS ONE 2017, 12, e0175584. [CrossRef]

9. Balla, C.S.; Kishan, N.; Gorla, R.S.R.; Gireesha, B.J. MHD boundary layer flow and heat transfer in an inclined porous square cavity filled with nanofluids. Ain Shams Eng. J. 2017, 8, 237-254. [CrossRef] 
10. Choi, S.U.S.; Eastman, J.A. Enhancing thermal conductivity of fluids with nanoparticle. Mater. Sci. 1995, 231, 99-105.

11. Nakhjavani, M.; Nikkhah, V.; Sarafraz, M.M.; Shoja, S.; Sarafraz, M. Green synthesis of silver nanoparticles using green tea leaves: Experimental study on the morphological, rheological and antibacterial behaviour. Heat Mass Transf. 2017, 53, 3201-3209. [CrossRef]

12. Kamalgharibi, M.; Hormozi, F.; Zamzamian, S.A.H.; Sarafraz, M.M. Experimental studies on the stability of $\mathrm{CuO}$ nanoparticles dispersed in different base fluids: Influence of stirring, sonication and surface active agents. Heat Mass Transf. 2016, 52, 55-62. [CrossRef]

13. Buongiorno, J. Convective transport in nanofluids. J. Heat Transf. 2006, 128, 240-250. [CrossRef]

14. Zaimi, K.; Ishak, A.; Pop, I. Boundary layer flow and heat transfer over a nonlinearly permeable stretching/shrinking sheet in a nanofluid. Sci. Rep. 2014, 4, 4404. [CrossRef] [PubMed]

15. Anwar, M.I.; Shafie, S.; Hayat, T.; Shehzad, S.A.; Salleh, M.Z. Numerical study for MHD stagnation-point flow of a micropolar nanofluid towards a stretching sheet. J. Braz. Soc. Mech. Sci. Eng. 2017, 39, 89-100. [CrossRef]

16. Sandeep, N.; Kumar, M.S. Heat and Mass Transfer in Nanofluid Flow over an Inclined Stretching Sheet with Volume Fraction of Dust and Nanoparticles. J. Appl. Fluid Mech. 2016, 9, 2205-2215. [CrossRef]

17. Suriyakumar, P.; Devi, S.A. Effects of Suction and Internal Heat Generation on Hydromagnetic Mixed Convective Nanofluid Flow over an Inclined Stretching Plate. Eur. J. Adv. Eng. Technol. 2015, 2, 51-58.

18. Ziaei-Rad, M.; Kasaeipoor, A.; Rashidi, M.M.; Lorenzini, G. A Similarity Solution for Mixed-Convection Boundary Layer Nanofluid Flow on an Inclined Permeable Surface. J. Therm. Sci. Eng. Appl. 2017. [CrossRef]

19. Rashad, A. Unsteady nanofluid flow over an inclined stretching surface with convective boundary condition and anisotropic slip impact. Int. J. Heat Technol. 2017, 35, 82-90. [CrossRef]

20. Mitra, A. Computational Modelling of Boundary-Layer Flow of a Nano fluid Over a Convective Heated Inclined Plate. J. Mech. Contin. Math. Sci. 2018, 13, 88-94. [CrossRef]

21. Khan, M.; Shahid, A.; Malik, M.Y.; Salahuddin, T. Thermal and concentration diffusion in Jeffery nanofluid flow over an inclined stretching sheet: A generalized Fourier's and Fick's perspective. J. Mol. Liq. 2018, 251, 7-14. [CrossRef]

22. Hatami, M.; Jing, D.; Yousif, M.A. Three-dimensional analysis of condensation nanofluid film on an inclined rotating disk by efficient analytical methods. Arab J. Basic Appl. Sci. 2018, 25, 28-37. [CrossRef]

23. Rafique, K.; Anwar, M.I.; Misiran, M. Keller-box study on casson nano fluid flow over a slanted permeable surface with chemical reaction. Asian Res. J. Math. 2019, 14, 1-17. [CrossRef]

24. Eckert, E.R.G.; Drake, R.M., Jr. Analysis of Heat and Mass Transfer; Hemisphere Publishing: New York, NY, USA, 1987.

25. Bég, O.A.; Bég, T.A.; Bakier, A.Y.; Prasad, V.R. Chemically-reacting mixed convective heat and mass transfer along inclined and vertical plates with Soret and Dufour effects: Numerical solutions. Int. J. Appl. Math. Mech. 2009, 5, 39-57.

26. Pal, D.; Chatterjee, S. Soret and Dufour effects on MHD convective heat and mass transfer of a power-law fluid over an inclined plate with variable thermal conductivity in a porous medium. Appl. Math. Comput. 2013, 219, 7556-7574. [CrossRef]

27. Balla, C.S.; Naikoti, K. Soret and Dufour effects on free convective heat and solute transfer in fluid saturated inclined porous cavity. Eng. Sci. Technol. Int. J. 2015, 18, 543-554. [CrossRef]

28. Eringen, A.C. Theory of micropolar fluids. J. Math. Mech. 1966, 16, 1-18. [CrossRef]

29. Eringen, A.C. Theory of thermomicrofluids. J. Math. Anal. Appl. 1972, 38, 480-496. [CrossRef]

30. Ariman, T.M.A.N.D.; Turk, M.A.; Sylvester, N.D. Microcontinuum fluid mechanics-A review. Int. J. Eng. Sci. 1973, 11, 905-930. [CrossRef]

31. Qukaszewicz, G. Micropolar Fluids: Theory and Application; Springer: Berlin/Heidelberg, Germany, 1999.

32. Eringen, A.C. Microcontinuum Field Theories, II; Fluent Media: New York, NY, USA, 2001.

33. Rahman, M.M.; Aziz, A.; Al-Lawatia, M.A. Heat transfer in micropolar fluid along an inclined permeable plate with variable fluid properties. Int. J. Therm. Sci. 2010, 49, 993-1002. [CrossRef]

34. Das, K. Slip effects on heat and mass transfer in MHD micropolar fluid flow over an inclined plate with thermal radiation and chemical reaction. Int. J. Numer. Methods Fluids 2012, 70, 96-113. [CrossRef]

35. Kasim, A.R.M.; Mohammad, N.F.; Shafie, S. Unsteady MHD mixed convection flow of a micropolar fluid along an inclined stretching plate. Heat Transf. Asian Res. 2013, 42, 89-99. 
36. Srinivasacharya, D.; Bindu, K.H. Entropy generation in a micropolar fluid flow through an inclined channel. Alex. Eng. J. 2016, 55, 973-982. [CrossRef]

37. Hazbavi, A.; Sharhani, S. Micropolar Fluid Flow Between Two Inclined Parallel Plates. In ASME 2017 International Mechanical Engineering Congress and Exposition; American Society of Mechanical Engineers: New York, NY, USA, 2017.

38. Shamshuddin, M.D.; Mishra, S.R.; Bég, O.A.; Kadir, A. Unsteady reactive magnetic radiative micropolar flow, heat and mass transfer from an inclined plate with joule heating: A model for magnetic polymer processing. Proc. Inst. Mech. Eng. Part C J. Mech. Eng. Sci. 2018, 233, 1246-1261. [CrossRef]

39. Srinivasacharya, D.; RamReddy, C.; Naveen, P. Double dispersion effect on nonlinear convective flow over an inclined plate in a micropolar fluid saturated non-Darcy porous medium. Eng. Sci. Technol. 2018, 21, 984-995. [CrossRef]

40. Rafique, K.; Anwar, M.I.; Misiran, M. Numerical Study on Micropolar Nanofluid Flow over an Inclined Surface by Means of Keller-Box. Asian J. Probab. Stat. 2019, 4, 1-21. [CrossRef]

41. Mishra, S.R.; Baag, S.; Mohapatra, D.K. Engineering Science and Technology, an International Journal Chemical reaction and Soret effects on hydromagnetic micropolar fluid along a stretching sheet. Eng. Sci. Technol. 2016, 19, 1919-1928. [CrossRef]

42. Khan, W.A.; Pop, I. Boundary-layer flow of a nanofluid past a stretching sheet. Int. J. Heat Mass Transf. 2010, 53, 2477-2483. [CrossRef]

(C) 2019 by the authors. Licensee MDPI, Basel, Switzerland. This article is an open access article distributed under the terms and conditions of the Creative Commons Attribution (CC BY) license (http://creativecommons.org/licenses/by/4.0/). 